\title{
Unraveling the contributions of the diencephalon to recognition memory: A review
}

\author{
John P. Aggleton, ${ }^{1,3}$ Julie R. Dumont, ${ }^{1}$ and Elizabeth Clea Warburton ${ }^{2}$ \\ ${ }^{1}$ School of Psychology, Cardiff University, Cardiff, CF10 3AT, Wales, United Kingdom; ${ }^{2}$ MRC Centre for Synaptic Plasticity, School of \\ Physiology, University of Bristol, Bristol BS8 1TD, United Kingdom
}

\begin{abstract}
Both clinical investigations and studies with animals reveal nuclei within the diencephalon that are vital for recognition memory (the judgment of prior occurrence). This review seeks to identify these nuclei and to consider why they might be important for recognition memory. Despite the lack of clinical cases with circumscribed pathology within the diencephalon and apparent species differences, convergent evidence from a variety of sources implicates a subgroup of medial diencephalic nuclei. It is supposed that the key functional interactions of this subgroup of diencephalic nuclei are with the medial temporal lobe, the prefrontal cortex, and with cingulate regions. In addition, some of the clinical evidence most readily supports dual-process models of recognition, which assume two independent cognitive processes (recollective-based and familiarity-based) that combine to direct recognition judgments. From this array of information a "multi-effect multinuclei" model is proposed, in which the mammillary bodies and the anterior thalamic nuclei are of preeminent importance for recollective-based recognition. The medial dorsal thalamic nucleus is thought to contribute to familiarity-based recognition, but this nucleus, along with various midline and intralaminar thalamic nuclei, is also assumed to have broader, indirect effects upon both recollective-based and familiarity-based recognition.
\end{abstract}

Clinical studies repeatedly show that diencephalic pathology can impair recognition memory. Even so, there is no agreed locus within the diencephalon responsible for this memory loss and, hence, no agreed mechanism to explain the impairment. The present review examines both clinical and animal findings, and from this information a multi-effect multi-nuclei (MEMN) model emerges to explain the contributions of the diencephalon to recognition memory.

At the outset, it is necessary to refine the focus of this review and to define some of its principal terms. The diencephalon comprises the thalamus and hypothalamus but, as will be explained, only the more medial parts of the diencephalon will be considered in detail. Recognition memory refers to the ability to detect whether a stimulus (e.g., a word, face, picture, object, or sound) has previously been encountered. As a consequence, this review is not about item identification (sometimes also confusingly referred to as recognition). Likewise, conditions that have broad disruptive effects on cognition, e.g., dementia, will not be considered even though recognition is typically impaired. Distinctions will be made between "item recognition," where the task is to determine if an individual item is novel or familiar, and "associative recognition," where all the individual items being experienced are familiar, but their particular combination is novel. A further, distinct ability is "recency" discrimination-the ability to determine which of two familiar stimuli has been experienced more recently. Both studies of amnesia and electrophysiological recordings show how recency memory and recognition can be dissociated (Milner et al. 1991; Shaw and Aggleton 1995; Brown and Aggleton 2001), underlining the importance of maintaining this distinction.

As noted above, this review will focus on more medial structures within the diencephalon. The principal reason for this focus is that when diencephalic pathology severely impairs recognition

${ }^{3}$ Corresponding author.

E-mail aggleton@cf.ac.uk; fax 442920874858.

Article is online at http://www.learnmem.org/cgi/doi/10.1101//m.1884611. memory, the deficit is largely confined to people with anterograde amnesia (e.g., Graff-Radford et al. 1990; Aggleton and Shaw 1996; Carlesimo et al. 2011). As anterograde amnesia is associated with medial, not lateral diencephalic, injury (Victor et al. 1971; Aggleton and Brown 1999; Van der Werf et al. 2000, 2003a,b), this review mainly considers the anterior, medial dorsal, intralaminar, and midline thalamic nuclei-all medially located thalamic nuclei. Within the medial hypothalamus, attention is largely given to the mammillary bodies, given the persistent links between pathology in these nuclei and anterograde amnesia (Vann and Aggleton 2004).

The following sections discuss relevant human and animal findings. The human findings are principally taken from clinical studies involving the cognitive impact of brain pathology. A pervasive problem with the clinical evidence is that the pathology almost invariably involves multiple nuclei, along with associated disconnections of fiber pathways within the thalamus. This problem is exacerbated by the anatomical limitations of magnetic resonance imaging (MRI), which means that it is often not possible to identify individual diencephalic nuclei with any certainty.

A final issue concerns the connectivity of the medial diencephalon (Fig. 1). This region has many direct connections with other areas already implicated in recognition memory, most notably the medial temporal lobe (Aggleton and Saunders 1997; Saunders et al. 2005) and the prefrontal cortex (Kievet and Kuypers 1977; Carmichael and Price 1995). The effects of damage to these connections on recognition memory are clearly relevant to the present review. Many of the projections from the medial temporal lobe to the medial diencephalon (e.g., to the mammillary bodies, anterior thalamic nuclei, and midline thalamic nuclei) rely on the fornix (Aggleton et al. 1986; Saunders et al. 2005), and so the impact of fornix lesions will briefly be considered. At the same time, the fornix contains many connections with sites outside the diencephalon (Saunders and Aggleton 2007) and so such findings need to be interpreted with care. Another potentially important route is the inferior thalamic peduncle (Fig. 1), by which the parahippocampal region reaches 

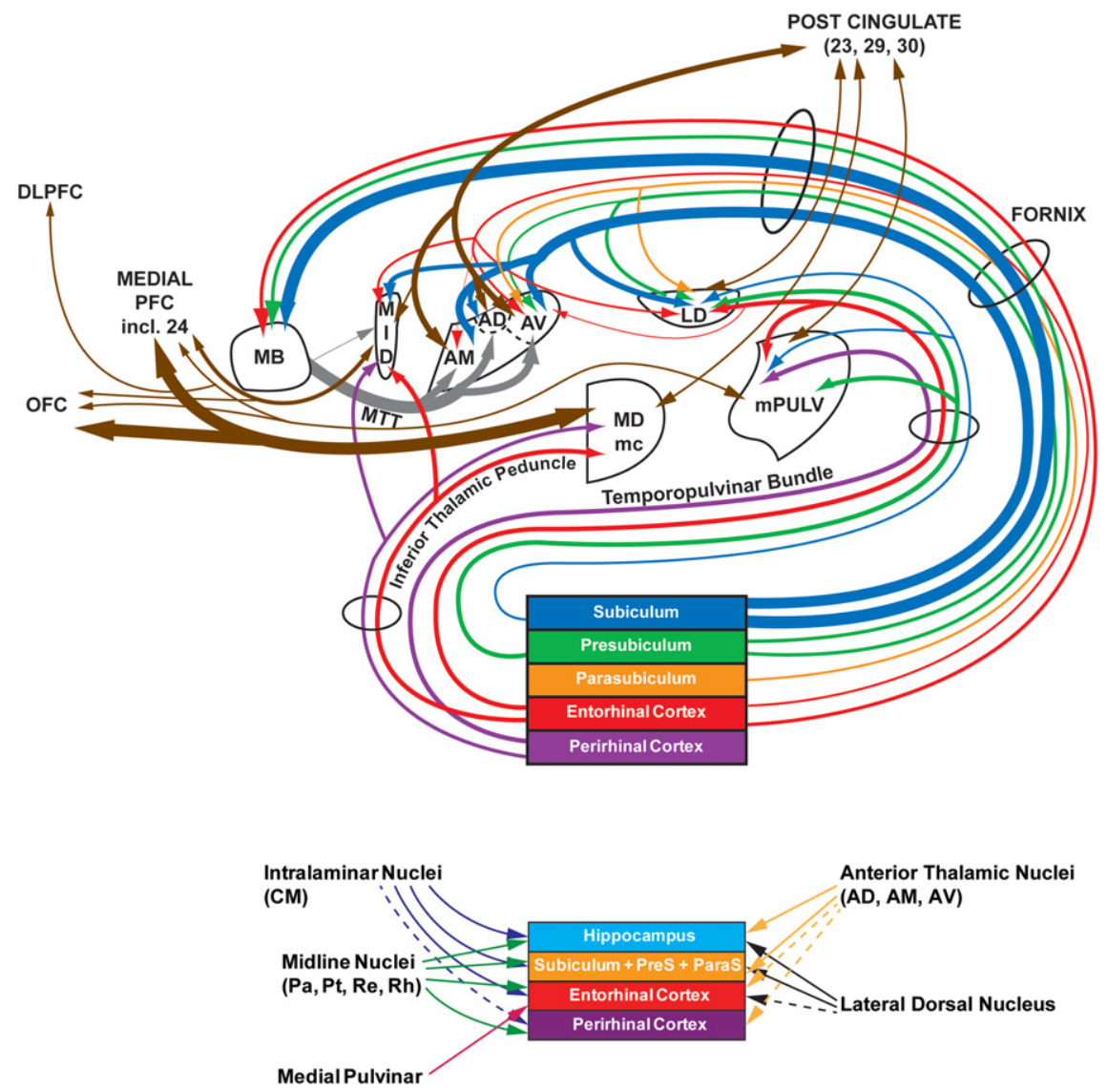

Figure 1. (Upper) Summary diagram showing the key connections in the macaque monkey of those medial diencephalic nuclei that form the focus of this review. The emphasis is on diencephalic connections with the medial temporal lobe and with the prefrontal cortex, and, for this reason, the various, direct cortico-cortical connections between the medial temporal lobe, posterior cingulate cortices, and prefrontal cortex are not depicted. It should be noted that none of the medial temporal projections to the medial diencephalon originate in the hippocampus proper. The thickness of the lines reflects the density of each projection. (Lower) Summary of thalamic projections to the hippocampus and rhinal cortices in macaque monkeys (Amaral and Cowan 1980; DeVito 1980; Insausti et al. 1987; Gower 1989). Dashed lines represent light projections. Abbreviations: AD, anterior dorsal nucleus; AM, anterior medial nucleus; AV, anterior ventral nucleus; CM, center median nucleus; DLPFC, dorsolateral prefrontal cortex; LD, lateral dorsal nucleus; $\mathrm{MB}$, mammillary bodies; $\mathrm{MD}$, medial dorsal nucleus, including pars magnocellular (mc); mPULV, medial pulvinar; MTT, mammillothalamic tract; OFC, orbital frontal cortex; Pa, paraventricular nucleus; PFC, prefrontal cortex; Pt, parataenial nucleus; Re, nucleus reuniens; Rh, rhomboid nucleus. The numbers correspond to cortical areas.

the medial dorsal thalamus (Aggleton and Mishkin 1984; GraffRadford et al. 1990; Saunders et al. 2005).

\section{Findings from clinical studies}

Both unilateral and bilateral diencephalic pathology will be considered. Unilateral diencephalic lesions often have material specific effects. For, example, an extensive stroke involving the left medial thalamus severely impaired the recognition of verbal material but left intact the recognition of abstract designs and scenes (Parkin et al. 1994; see also Pepin and Auray-Pepin 1993; Clarke et al. 1994; Van der Werf et al. 2000). In contrast, a stroke seemingly confined to the anterior part of the right thalamus (mamillothalamic tract and anterior parts of lateral thalamus but not the medial dorsal nucleus) produced visuospatial memory deficits, including poor face recognition, yet left word recognition in the normal range (Daum and Ackermann 1994; see also Pepin and Auray-Pepin 1993). In other cases, however, a seemingly unilateral insult can affect both verbal and nonverbal material (Carlesimo et al. 2011).

\section{Does selective diencephalic pathology impair recognition memory? Postmortem studies}

The first task is to confirm whether pathology restricted to the diencephalon is sufficient to impair recognition memory. Here, postmortem data should provide the necessary histological verification. Issues still remain, however, of whether all regions of interest had been examined in each case and whether some chronic brain dysfunctions are not revealed by standard histological means (Finger et al. 2004; Aggleton 2008). This latter issue is particularly relevant to thalamic pathology, which has often been linked to cortical "diaschisis" (Baron et al. 1986; Levasseur et al. 1992; Van der Werf et al. 2002). The term diaschisis refers to both temporary and long-lasting abnormal changes (e.g., edema, changes in blood flow) to regions outside the immediate area of brain trauma (Von Monokow 1911; Finger et al. 2004). A further problem is that many postmortem reports are accompanied by only brief descriptions of the cognitive status of the patient prior to death.

Most postmortem reports linking memory loss with diencephalic pathology refer to the amnesic Korsakoff's syndrome. All Korskoff patients suffer medial diencephalic pathology that includes the medial mammillary bodies (e.g., Victor et al. 1971; Mair et al. 1979; Harding et al. 2000), and almost every case has severe recognition memory deficits (Aggleton and Shaw 1996). There remains, however, the problem that in this condition there is often additional pathology outside the diencephalon (Victor et al. 1971; Kopelman et al. 2009). Consequently, it is necessary to focus on those very few cases of diencephalic amnesia, including Korsakoff's syndrome, where the pathology seems confined to the diencephalon and where specific recognition memory deficits have been established.

Two alcoholic Korsakoff patients were described by Mair et al. (1979), both of whom had very severe impairments on forcedchoice recognition yet a reasonably intact IQ. Postmortem histology in both cases revealed severe neuronal loss in just the medial mammillary nucleus and the thalamic parataenial nucleus, just medial to the preserved medial dorsal nucleus. In one of these cases, there was additional diffuse gliosis across the thalamus. No other nerve loss was apparent (Mair et al. 1979). A very similar postmortem pattern (medial mammillary bodies and midline thalamus) was reported in two further alcoholic Korsakoff patients who were very impaired at yes/no recognition (Mayes et al. 1988). A fifth Korsakoff patient, PN, had a moderate recognition deficit and was found to have suffered damage to the mammillary bodies, the mammillothalamic tract, and the anterior thalamic nuclei, all confirmed postmortem (Gold and Squire 
2006). All other thalamic nuclei, including the medial dorsal and midline (including parataenial) nuclei, appeared normal (Gold and Squire 2006).

Other etiologies that affect the diencephalon (e.g., tumors and strokes) can also impair recognition memory. Stroke case MG showed moderate deficits in word and face recognition, associated with bilateral thalamic pathology that was initially determined from MRI scans but then confirmed postmortem (Gold and Squire 2006). Unfortunately, a second stroke just prior to MG's death added to her postmortem pathology, as it caused extensive damage to the right thalamus and right internal capsule. In the left hemisphere, MG's pathology was largely localized in the intralaminar nuclei (paracentral nucleus, central medial nucleus, and central lateral) along with parts of medial dorsal nucleus and the ventral lateral nucleus (Gold and Squire 2006). The implication is that damage to these more posterior thalamic nuclei can impair recognition memory.

\section{Which are the key nuclei within the diencephalon responsible for recognition memory deficits?}

Having established that pathology seemingly restricted to the diencephalon can impair recognition memory, this section examines evidence concerning the importance of particular nuclei or tracts within the region. The specific issue of whether different diencephalic nuclei might contribute to separate components of recognition memory, e.g., familiarity or recollection (see Yonelinas 2002), will be examined in the section "Testing for the impact of diencephalic pathology on components of recognition memory."

\section{Mammillary bodies and mammillothalamic tract}

All of the relevant clinical evidence concerning the hypothalamus involves either the mammillary bodies or its efferent pathway, the mammillothalamic tract. As noted above, patients with the amnesic Korsakoff's syndrome all suffer pronounced cell loss in the medial mammillary nucleus (Victor et al. 1971; Mair et al. 1979; Mayes et al. 1988; Gold and Squire 2006), and almost all cases show severely impaired recognition (Aggleton and Shaw 1996). An intriguing exception was a 20 -yr-old alcoholic woman diagnosed with Wernicke's disease who had excellent recognition memory yet profound recall (verbal and nonverbal) impairments (Parkin et al. 1993). Despite the absence of MRI data for this single case, it would seem almost inevitable that she suffered bilateral mammillary body atrophy (Victor et al. 1971; Harding et al. 2000) yet showed spared recognition.

More direct evidence that mammillary body damage can partially spare recognition memory comes from the extraordinary case of patient BJ who was stabbed with a snooker cue (Dusoir et al. 1990). BJ suffered bilateral mammillary damage, and, when tested between 1 and 2 yr post-injury (Dusoir et al. 1990; Kapur et al. 1994), he was markedly impaired on verbal recall tests yet showed seemingly normal recognition performance, e.g., on the Recognition Memory Test (RMT) (Warrington 1984). A second patient (NA) suffered more extensive brain injury after a miniature fencing foil penetrated his nose (Squire et al. 1989) and so is more difficult to interpret. NA had bilateral mammillary body pathology combined with unilateral (left-sided) pathology in the region of nucleus reuniens and the intralaminar nuclei (central medial, paracentral, and parafascicular), and parts of the medial dorsal, ventral lateral, and ventral anterior nuclei. Patient NA showed predominantly verbal memory problems that included a mild deficit for forced-choice recognition of words, but he performed in the middle of the normal range for face recognition despite bilateral mammillary body damage (Squire et al. 1989). These cases
(BJ and NA) indicate that bilateral mammillary body damage can largely spare recognition memory despite the strong link between this region and other forms of memory (Vann and Aggleton 2004).

Cases with tumors centered in the region of the mammillary bodies display very similar changes to those reported for BJ, i.e., a consistent deficit on tests of delayed recall but only mild recognition memory deficits. For example, a young adult with bilaterally atrophied mammillary bodies after surgical removal of a germinoma showed impaired recall but almost intact recognition (Hildebrandt et al. 2001). Two cases (Kapur et al. 1998) in which the mammillary bodies appear to have been lost following suprasellar tumors again showed either normal recognition (case TG) or only mild deficits on word recognition, while face recognition seemed intact (case SJ). One potential concern is that, in these single case studies, the premorbid levels of recognition are not known, inevitably making it difficult to detect small deficits. Group studies can help address this problem.

One of the largest group studies examined 38 patients, all of whom had colloid cysts surgically removed from the third ventricle (Tsivilis et al. 2008). Although the patients suffered variable damage to the fornix, the most persistent atrophy was in the mammillary bodies (Denby et al. 2009). A battery of recall and recognition tests established a very clear pattern of results, with mammillary body volume correlating with recall performance (small mammillary bodies, poor recall) but not correlating with recognition. Further comparisons were then made between those eleven cases with the smallest mammillary bodies and those eleven cases with the largest (i.e., near normal-sized) mammillary bodies (Tsivilis et al. 2008). Both groups suffered the same neurological disorder, received comparable surgeries, and did not differ in age or IQ. Furthermore, the measurement of other brain regions showed that the volumes of other regions of interest (aside from the fornix) were not reduced in the group with the smaller mammillary bodies. Despite the fact that the two groups were so wellmatched, highly significant dissociations were found between their recall and recognition scores (Fig. 2; Tsivilis et al. 2008). The group with small mammillary bodies was consistently impaired on tests of recall, yet the two groups did not differ on measures of recognition memory, which were typically within

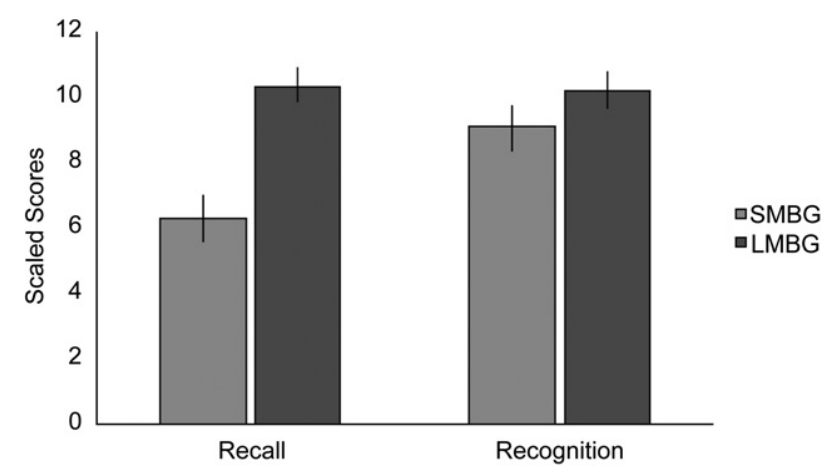

Figure 2. Mammillary body atrophy is associated with disproportionate recall vs. recognition impairments (Tsivilis et al. 2008). The graph shows recall and recognition scores (and standard error) for the 11 colloid cyst cases with the smallest mammillary bodies (SMBG) from a total of 38 cases. The scaled scores are compiled from multiple tests (WMS-III, Warrington RMT, and the Doors and People Test). The comparison scores are those of the 11 colloid cyst cases with the largest mammillary body volumes (LMBG) from the same pool of 38 cases. The $y$-axis shows the mean scaled scores, and so a normal population would be expected to have a mean $\approx 10.0$. Patients with the smallest mammillary bodies were significantly impaired on recall but not recognition. 
the normal range. The conclusion, once again, is that mammillary body damage has only very mild effects on standard tests of recognition yet can markedly disrupt the recall of episodic information. This conclusion receives additional support from a study of 65 patients with pituitary tumors (Gratton-Smith et al. 1992). Although that study did not include MRI evidence, the tumors are very likely to have invaded the posterior hypothalamus (including the mammillary bodies). The two groups of patients (subdivided between radiotherapy or no radiotherapy treatment) were both clearly impaired on tests taxing the delayed recall of verbal and nonverbal material, but their performance on the Warrington RMT did not differ from that of the controls (Gratton-Smith et al. 1992).

Overall, there is a very consistent pattern. Bilateral mammillary body damage impairs the delayed recall of new test material, while performance on tests of recognition seems only mildly disrupted. Indeed, in some studies there is no apparent deficit on standard tests of recognition. Perhaps the only exception to this pattern is a patient with a craniopharyngioma described by Beglinger et al. (2006). The patient was severely impaired on the Warrington RMT for both words and faces and had persistent recall deficits. The pathology in this case is, however, complex, as there was an additional anterior communicating artery aneurysm and MRI evidence of bilateral loss of not just the mammillary bodies and the mammillothalamic tract but also the columns of the fornix, as well as unilateral damage to the head of the caudate and putamen (Beglinger et al. 2006). Aside from this single case, there is overwhelming clinical evidence that when damage is largely confined to the mammillary bodies, there is a relative sparing of recognition compared to recall.

\section{The anterior thalamic nuclei}

The anterior thalamic nuclei comprise the anterior medial, anterior ventral, and anterior dorsal nuclei. These thalamic nuclei are sometimes called "limbic" because of their dense interconnections with the mammillary bodies, the hippocampal formation, and retrosplenial cortex (Fig. 1). A fourth thalamic nucleus, lateral dorsal, can be included in this anterior group, as it shares many of these same limbic connections (Bentivoglio et al. 1993) and has similar electrophysiological properties to the anterior dorsal thalamic nucleus (Taube 2007). A major difference is that the lateral dorsal nucleus lacks dense inputs from the mammillary bodies (Vann et al. 2007).

Much of the evidence concerning the importance of the anterior thalamic nuclei for memory comes from the impact of mammillothalamic tract damage, i.e., damage to the tract formed by the projections from the mammillary bodies to the anterior thalamic nuclei. Comparisons of when thalamic strokes do and do not induce amnesia have consistently found that damage to this tract is the best predictor of memory loss (Von Cramon et al. 1985; Ghika-Schmid and Bogousslavsky 2000; Van der Werf et al. 2000, 2003b; Carrera et al. 2004). One of these studies also linked recognition deficits to mammillothalamic tract damage (Van der Werf et al. 2003b). Unfortunately, the recognition tests were based on material previously acquired and tested in recall tests, making the specificity of any recognition impairments far more difficult to determine (Tsivilis et al. 2008).

A recent review (Carlesimo et al. 2011), which combined the findings from 41 previous studies of patients with thalamic strokes (including Van der Werf et al. 2003b), considered a total of 83 patients with vascular infarcts confirmed by MRI or CT. Of the 55 patients with presumed mammillothalamic tract damage, $95 \%$ had evidence of anterograde amnesia, but only $46 \%$ of the 28 patients without mammillothalamic tract damage had amnesia (Carlesimo et al. 2011). One of the former patients was a 38-yr-old man (GP) who suffered a stroke that resulted in bilateral damage to the mammillothalamic tract and the ventral anterior nucleus, along with unilateral damage to the right inferior thalamic peduncle (Carlesimo et al. 2007). The medial dorsal thalamic nucleus appeared intact. Patient GP was particularly poor on the free recall of episodic memory but showed normal performance levels on two-choice recognition (both verbal and nonverbal), though was impaired on yes/no word recognition and on some multiple-choice recognition tests (Carlesimo et al. 2007).

Other relevant evidence comes from the growing appreciation that anterior thalamic atrophy and dysfunction is particularly associated with the memory loss in Korsakoff's syndrome (Harding et al. 2000; Gold and Squire 2006). While problems persist concerning the nonspecific nature of the etiology, such findings add to the weight of evidence that these nuclei have an important role in declarative memory.

A more direct test of the importance of the anterior thalamic nuclei would be to determine the cognitive profiles of patients with ischemic accidents confined to these nuclei. The vascular supply to the thalamus is not, however, segregated according to nuclear borders (Castaigne et al. 1981), and strokes typically have unilateral or asymmetric effects that partially involve multiple nuclei. A further problem is posed by the concentration of white matter tracts that pass through the rostral thalamic area. These tracts include the inferior thalamic peduncle, which carries projections from the medial temporal lobe to the medial thalamic nuclei (Aggleton and Mishkin 1984; Aggleton et al. 1986), and projections to and from the prefrontal cortex (Kievet and Kuypers 1977).

Given these constraints, it is notable that Clarke et al. (1994) described a person with a small polar infarct thought to be largely limited to the left anterior thalamic nuclei, the anterior part of the left internal medullary lamina, and the adjacent mammillothalamic tract. The medial dorsal nucleus seemed to be largely spared. A persistent deficit was observed for the recall of verbal material, and recognition memory deficits were found for words but not faces when tested shortly after the stroke (Clarke et al. 1994). A PET study in the same patient showed decreased glucose metabolism in the posterior cingulate cortex, consistent with anterior thalamic nuclei damage (see Aggleton 2008). In a related study, four patients with bilateral medial thalamic infarcts were tested on the Warrington RMT (Graff-Radford et al. 1990). The two patients with the most severe anterograde amnesias $(\# 1,2)$ both suffered the more rostral thalamic strokes, including damage to the mammillothalamic tract, but it was the patient with bilateral damage to the inferior thalamic peduncle in addition to the mammillothalamic tract who was the most amnesic and the most consistently impaired on forced-choice recognition (see also Parkin et al. 1994). The implication from this second study is that damage additional to that in the anterior thalamic nuclei is required to cause severe recognition deficits.

Information concerning the fourth anterior thalamic nucleus, the lateral dorsal nucleus, is currently very limited. One intriguing finding concerns patient QX (Edelstyn et al. 2002,2006 ) who is thought to have suffered bilateral pathology in the lateral dorsal nucleus, while all of his other pathology, which included the left medial dorsal nucleus, was unilateral (Edelstyn et al. 2002). Patient QX showed clear verbal recall deficits with some evidence of a relative sparing of word recognition (Warrington RMT), while face recognition appeared unaffected. The implication is that, if bilateral pathology is required to produce clear memory deficits, then the lateral dorsal nucleus is potentially more important for recall than recognition.

The overall pattern is that anterior thalamic damage or disconnection is associated with recognition memory deficits, but these deficits need not be particularly severe [see also case PN 
(Gold and Squire 2006)]. An obvious problem is that, in all relevant cases, there is additional diencephalic damage. Even so, the potential association between these nuclei and recognition is underpinned by convergent evidence that anterior thalamic nuclei dysfunction contributes to anterograde amnesia (Aggleton and Sahgal 1993; Aggleton and Brown 1999; Harding et al. 2000; Van der Werf et al. 2000, 2003b), supported by the presence of reciprocal connections between the hippocampal formation and the anterior thalamic nuclei (Fig. 1; Amaral and Cowan 1980; DeVito 1980; Aggleton et al. 1986). While the clinical findings suggest that the anterior thalamic nuclei may be more important for recognition than the mammillary bodies, this difference needs further scrutiny. There remains, for example, the real possibility that any additional recognition problems arise from damage to white matter close to the anterior thalamic nuclei, e.g., the inferior thalamic peduncle and the internal medullary lamina.

\section{Medial dorsal thalamic nucleus}

In a thorough analysis of clinical findings, Markowitsch (1982) concluded that damage confined to the medial dorsal nucleus is not sufficient to induce consistent memory deficits (including recognition). The author, who argued that the disruption of more than one thalamic site or related pathways is required to induce severe and enduring memory deficits (Markowitsch 1982), had to rely either on postmortem findings (typically in studies with poor psychometric data) or on CT studies (typically with better psychometric data but limited anatomical resolution). The present review, which examines more recent cases and focuses on just recognition memory, largely supports this overall conclusion.

Of the four cases described by Graff-Radford et al. (1990), case \#4 had small bilateral lesions in the lower part of the medial dorsal nucleus and showed very good recognition. Case \#3 had large, bilateral lesions centered on the medial dorsal nucleus and also performed well on word and face recognition (RMT), though may have later shown a decrement on face recognition. The authors concluded that combined damage to the mammillothalamic tract and the inferior thalamic peduncle (which contains projections to the medial dorsal nucleus) (Fig. 1) best predicted anterograde amnesia (Graff-Radford et al. 1990), as the mammillothalamic tract was spared in cases \#3 and 4.

A similar failure to find a close link between direct medial dorsal nucleus damage and recognition was found in a systematic review of 60 patients from 35 articles relating thalamic damage to cognitive deficits (Van der Werf et al. 2000). It was concluded that executive memory problems were more associated with the medial dorsal thalamic region, while recall deficits were associated with pathology in the mammillothalamic tract/anterior thalamic nuclei. A limitation of the review was that attention was given to memory problems in general, while specific issues relating to recognition memory were not considered (Van der Werf et al. 2000). This shortcoming was partially rectified in a subsequent analysis of 22 thalamic infarct cases (Van der Werf et al. 2003b). Of particular note was the report that verbal recognition appeared intact in those cases (\#1, 4, 6, and 16) where there was damage to the left medial dorsal nucleus but sparing of the mammillothalamic tract or left internal medullary lamina (a fiber route for many nuclei including the medial dorsal nucleus). Further evidence comes from a description of two people with strokes involving parts of the medial dorsal nucleus (one bilateral) who showed no apparent loss of memory (Kritchevsky et al. 1987). The mammillothalamic tract was spared in both cases, i.e., the pathology appeared particularly discrete.

A rather different conclusion, however, was drawn from the study of a man with a thalamic stroke that caused bilateral lesions centered on the medial dorsal nucleus (Isaac et al. 1998). The patient (DM) showed very clear, severe deficits in both recall and recognition, with verbal recognition especially poor. MRI analysis indicated a bilateral lesion through the ventrolateral thalamus that extended medially into the ventral part of the medial dorsal nucleus. The lesion was slightly larger on the left. Although the anterior thalamic nuclei appeared intact, there was evidence of atrophy in the left mammillary bodies (Isaac et al. 1998). While two stroke cases with varying amounts of medial dorsal nucleus damage (in one case, only on the left, the other bilateral) also showed recognition memory deficits (Cipolotti et al. 2008), in both cases there was additional damage in other thalamic nuclei, producing a complex pattern of pathology that is difficult to interpret. Another study implicating the medial dorsal nucleus described five patients with unilateral infarcts that involved the medial dorsal nucleus but spread into adjacent regions (Zoppelt et al. 2003). The patients showed impaired recognition.

In summary, the case that damage restricted to the medial dorsal nucleus is sufficient to impair recognition memory is unproven, given a number of findings that seem contrary (e.g., Van der Werf et al. 2003a,b). At the same time, there is much evidence that caudal medial thalamic damage involving the medial dorsal nucleus can affect cognition, in particular by disrupting executive function (Van der Werf et al. 2000, 2003a,b; Carlesimo et al. 2011). This outcome is not surprising given the intimate anatomical relationship between the medial dorsal thalamic nucleus and the prefrontal cortex and the importance of the prefrontal cortex for executive function. In those studies that suggest a more direct contribution for the medial dorsal nucleus to recognition (e.g., Isaac et al. 1998; Zoppelt et al. 2003; Cipolotti et al. 2008), there remain problems regarding the potential contributions from immediately adjacent nuclei and tracts, e.g., the internal medullary lamina.

\section{Intralaminar and midline thalamic nuclei}

A consideration of the connectivity of these nuclei immediately suggests a potential role in cognition. A number of midline nuclei, including reuniens, parataenial, paraventricular, and rhomboid, have appreciable inputs to the hippocampal formation, as well as to the perirhinal and entorhinal cortices (Fig. 1, lower; Amaral and Cowan 1980; DeVito 1980; Van der Werf et al. 2002; Vertes et al. 2007). The midline thalamic nuclei also have prefrontal connections that preferentially terminate in the orbital and medial cortices (Berendse and Groenewegen 1991; Van der Werf et al. 2002; Hsu and Price 2007; Vertes et al. 2007). Likewise, intralaminar nuclei project to parts of the medial and orbital prefrontal cortex, especially the cingulate region, as well as to sensory association areas (e.g., Yeterian and Pandya 1989; Hsu and Price 2007). In addition, the central medial nucleus (an intralaminar nucleus) projects to the hippocampal formation. The importance of the cortical projections from the intralaminar nuclei is highlighted by a series of clinical cases with paramedian thalamic infarcts that involved these nuclei (along with the medial dorsal nucleus) and who displayed widespread decreases in cortical metabolic activity (Levasseur et al. 1992).

The locations of the intralaminar and midline nuclei do, however, mean that it would be most unusual to find pathology just restricted to these nuclei. Indeed, the intralaminar nuclei are so called because many of them lie within the internal medullary lamina. One case that highlights these issues is that of a man with a discrete lacunar infarct in the right dorsal caudal intralaminar nuclei (Van der Werf et al. 1999). The pathology appeared to spare most of the adjacent medial dorsal nucleus but inevitably involved the internal medullary lamina. This patient showed inconsistent levels of recall, including poor performance on some 
recognition tests, but could not be regarded as amnesic (Van der Werf et al. 1999). On yes/no recognition tests, the patient had a tendency to make false positive responses, more indicative of perseverative problems than a loss of recognition memory per se. This interpretation was consistent with his other cognitive changes (apathy, a lack of attention, inflexibility) which also suggested prefrontal cortex dysfunction. Additional support for this view came from spectroscopy results showing decreased blood flow in the right frontal cortex (Van der Werf et al. 1999). A second patient was described with memory problems associated with pathology in the caudal intralaminar nuclei (e.g., including the center median nucleus and the parafascicular nucleus), but these problems appeared to be due to a loss of attention and increased distractibility (Mennemeier et al. 1992). Problems with arousal and levels of awareness have since been further linked with damage to the intralaminar nuclei (Van der Werf et al. 2002; Carrera et al. 2004) but again could reflect disconnections due to white matter damage.

Evidence regarding the midline thalamic nuclei comes from postmortem analyses of four alcoholic Korsakoff patients (Mair et al. 1979; Mayes et al. 1988) where the discernable thalamic pathology was largely confined to the parataenial nucleus. All four patients displayed severe recognition memory deficits. These findings are striking but difficult to interpret, as all four patients were chronic alcoholics and also suffered mammillary body atrophy. In addition, the parataenial nucleus has not been identified as a consistent site of pathology in numerous other postmortem studies of Korsakoff's syndrome (e.g., Victor et al. 1971; Gold and Squire 2006).

In conclusion, there are good reasons to suppose that at least some of the intralaminar and midline thalamic nuclei have a role in supporting aspects of learning and memory. One possibility is that they have a broad role in attention and arousal (Van der Werf et al. 2002) rather than a specific role in recognition. A pervasive problem is that the locations of the intralaminar nuclei are tightly related to fiber tracts, most especially the internal medullary lamina. Consequently, clinical studies of stroke cases are unlikely to give a definitive answer. A further issue is that, although these nuclei are sometime labeled as "nonspecific," it is now clear that the various intralaminar and midline nuclei each have individual patterns of connectivity with the potential for individual functions (Van der Werf et al. 2002).

\section{Testing for the impact of diencephalic pathology on components of recognition memory}

A striking feature of occasional diencephalic amnesic cases is the presence of severe recall deficits yet seemingly spared recognition (e.g., Dusoir et al. 1990; Hildebrandt et al. 2001; Carlesimo et al. 2007; Tsivilis et al. 2008). This profile would seem to accord with the predictions of a model initially proposed by Aggleton and Brown (1999). This model assumes that the hippocampal $\rightarrow$ mammillary body $\rightarrow$ anterior thalamic axis is critical for recollective-based recognition while the rostral parahippocampal $\rightarrow$ medial dorsal thalamic axis is critical for familiarity-based recognition. Recollective-based recognition refers to when the previous experience of an event can be verified against a recalled memory associated with the target stimulus (sometimes called a "remember" response). Familiarity refers to the feeling that a target has been experienced before in the absence of other explicit memories of that event (sometimes called a "know" response). This distinction comes from dual-process models of recognition memory that assume familiarity and recollection are independent processes (Mandler 1980; Yonelinas 2002). Hence, those cases with far more severe recall than recognition deficits are regarded as having spared familiarity information.
An alternative model assumes that recognition and recall draw on the same information and that the differences between recollection and familiarity lie in the strength of the trace (e.g., Squire et al. 2007). Weak traces give rise to a feeling of knowing (familiarity). while stronger information corresponds to remembering (recollection). The prediction is that restricted diencephalic pathology might partially reduce signal strength and so, partially affect recognition. The consequence may, however, be perceived as a disproportionate effect on recollective-like recognition. as any weak signal (perceived as familiarity) will remain. As diencephalic pathology increases and, thereby, involves more nuclei and tracts, so information processing will be increasingly compromised leading to impairments in both familiarity (knowing) and recollection (remembering). Because single-process models still assume that recognition and recall are derived from the same information, then the performance levels of these two kinds of memory tasks are interlocked and should not dissociate (assuming matched task difficulty). In contrast, dual-process models allow recall:recognition dissociations. A further key difference is that only dual-process models predict that neuropsychological cases might exist with a selective loss of familiarity information, i.e., spared recall compared to recognition.

There have been several direct tests of the predictions made by Aggleton and Brown (1999). One of the first came from studies into the impact of damage to the fornix, the tract by which the medial temporal lobe directly innervates the mammillary bodies and anterior thalamic nuclei (Fig. 1) as well as links other cortical and subcortical sites (Saunders and Aggleton 2007). The fornix does not, however, project to the medial dorsal nucleus. The Aggleton and Brown (1999) model predicts that (1) fornix damage is sufficient to induce amnesia, and (2) that there will be a sparing of familiarity-based recognition. Studies now show that patients with bilateral fornix damage following surgery for a colloid cyst do, indeed, show a severe memory loss but a relative sparing of recognition (e.g., McMackin et al. 1995; Aggleton et al. 2000; Vann et al. 2008). Furthermore, their pattern of performance appears consistent with a selective loss of recollective-based recognition (Aggleton et al. 2000; Vann et al. 2009a,b). Possibly the strongest evidence, so far, has come from comparing matched groups of colloid cyst patients who differed in the volumes of their fornices and mammillary bodies (Tsivilis et al. 2008; Vann et al. 2009a,b). The two groups showed comparable levels of recognition but very clear differences in recall (Fig. 2), as only the small mammillary body group was impaired on recall (Tsivilis et al. 2008). This recall:recognition dissociation was found for tests that included Doors and People, where task difficulty on the tests of recall and recognition has been equated (Baddeley et al. 1994). Next, remember/know and receiver operating characteristics (ROC) tests indicated that the patients with small mammillary bodies showed a significant loss of recollective-based recognition yet preserved familiarity-based recognition (Fig. 3; Vann et al. 2009a,b). Finally, structural equation modeling of the cognitive data from a larger cohort of 62 colloid cyst cases added further support to the dual-process interpretation of these psychometric findings (Fig. 3; Vann et al. 2009a,b).

Evidence of a similar dissociation was found in patient GP who suffered a stroke that resulted in bilateral damage to the mammillothalamic tract and the ventral anterior nucleus but only unilateral (right) damage to the inferior thalamic peduncle (Carlesimo et al. 2007). Tests using remember/know and ROC curves indicated that GP's recognition impairments reflect a selective loss of recollection, while familiarity detection is normal. Consequently, it can be seen that these results for the fornix, mammillary bodies, and mammillothalamic tract are consistent with the notion that these anatomically interlinked structures are especially important for (1) episodic memory and 


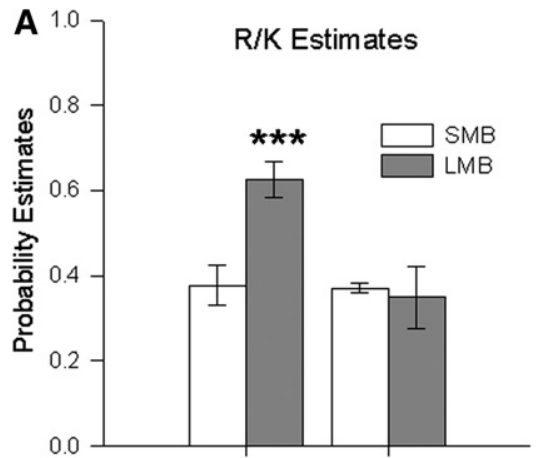

Recollection Familiarity
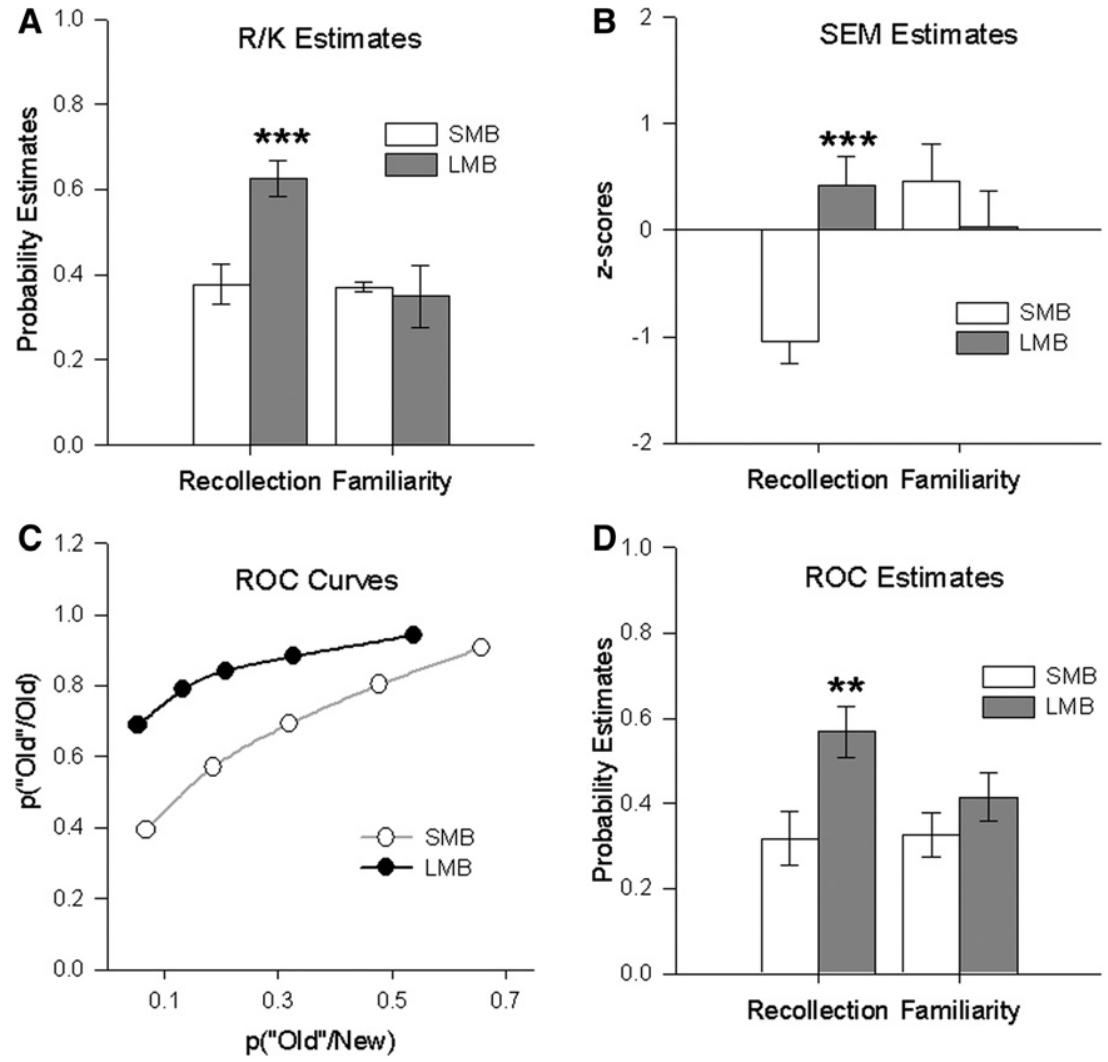

Recollection Familiarity

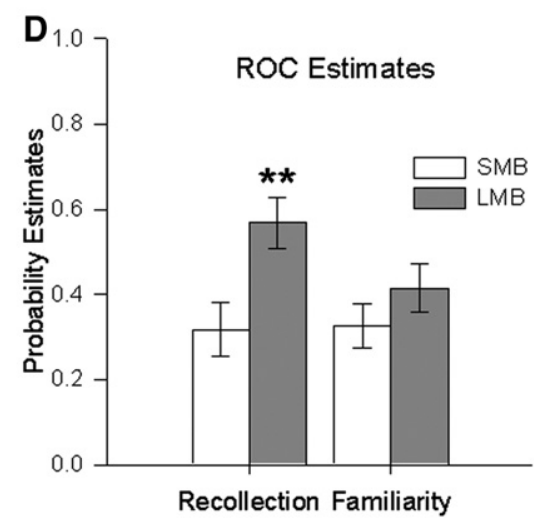

Figure 3. Evidence that mammillary body atrophy selectively disrupts recollective-based recognition (Vann et al. 2009a,b). Findings are shown for three tests designed to distinguish recollective-based from familiarity-based recognition. Colloid cyst patients were separated according to the size of their mammillary bodies to create two groups (both $n=9$ ) -small mammillary bodies (SMB) and large mammillary bodies $(\mathrm{LMB})$. Measures of recollection and familiarity were derived using the remember/know $(R /$ $\mathrm{K})$ procedure $(A)$ and receiver operating characteristic $(\mathrm{ROC})$ curves $(C)$, leading to estimates of recollection and familiarity derived from these ROC curves $(D)$. (B) The psychometric data from a larger group of 62 colloid cyst patients were also analyzed using structural equation modeling (SEM), and estimates of recollection and familiarity were derived from the best fit model. Data presented in histograms are means \pm standard error of the mean. Group differences: ${ }^{* *} P<0.01,{ }^{* * *} P<0.005$.

(2) recollective-based recognition. In contrast, these structures are not vital for familiarity information.

Other findings consistent with the predictions of Aggleton and Brown (1999) include those from a patient with bilateral anterior thalamic damage and partial medial dorsal thalamic pathology (Kishiyama et al. 2005). This patient displayed more severe recall than recognition deficits (Kishiyama et al. 2005). Use of remember/know and ROC procedures pointed to clear deficits in recollection, with smaller but consistent deficits in familiarity. Here, the combined pattern of recollection and familiarity deficits accords with the combined anterior and medial dorsal thalamic pathology (Aggleton and Brown 1999), with the more complete anterior thalamic damage linked to the more robust deficits in recollection.

Case QX suffered bilateral damage to the lateral dorsal thalamic nuclei, part of the anterior thalamic nuclei, along with left medial dorsal thalamic involvement (Edelstyn et al. 2006). His pattern of performance across recognition tasks was seen as reflecting a relative sparing of familiarity in the face of a recall deficit. The interpretation of this case is, however, difficult given the contrasting pattern of unilateral (medial dorsal) and bilateral (lateral dorsal) pathology and their relative impact. If it is assumed that bilateral pathology is of most significance, then this case would seem to fit the prediction of spared familiarity after anterior thalamic damage. The problem is that unilateral thalamic damage can have very variable effects on the extent of any memory loss (Carlesimo et al. 2011).

Less support for the two-process model of Aggleton and Brown (1999) comes from an analysis of nine patients with unilateral thalamic infarcts (Zoppelt et al. 2003). In five cases, the infarct involved the medial dorsal nucleus, while in four others the ventral lateral nucleus was damaged, prompting the opportunity to test whether damage to the medial dorsal nucleus might specifically impair familiarity (as predicted by Aggleton and Brown [1999]). Analyses using ROC curves for all nine thalamic patients in a single group indicated decreases in both recollection and familiarity (Zoppelt et al. 2003). There was no evidence that those patients with medial dorsal nucleus damage had a greater loss of familiarity (Zoppelt et al. 2003). However, in none of these cases was the pathology thought to be confined to one nucleus, and it can be assumed that the intralaminar nuclei and the internal medullary lamina would have been variably affected.

A further study of ten patients with ischemic thalamic lesions involving the medial dorsal nucleus and/or the ventrolateral nucleus compared performance on "relational" and "nonrelational" recognition memory tests (Soei et al. 2008). The relational tests (which examined the recognition of novel spatial configurations of familiar objects and novel pairing of familiar objects) were designed to tax associative recognition. The nonrelational test asked participants to identify novel viewpoints of familiar objects. The relational tasks appeared more sensitive to the thalamic pathology (Soei et al. 2008), suggesting that, in some cases, damage to the medial dorsal region can disrupt associative recognition of the sort likely to tax recollective-based recognition.

Another specific test of the Aggleton and Brown (1999) model involved two patients, both with bilateral thalamic infarcts and anterograde amnesia (Cipolotti et al. 2008). In patient 1 , the lesion on the left involved the medial dorsal thalamic nucleus and mammillothalamic tract, while on the right the pathology appeared more focused in the anterior thalamic nuclei (lateral dorsal and anterior ventral). In patient 2 , damage to the medial dorsal nucleus appeared bilateral, while the mammillothalamic tract/anterior thalamic pathology was essentially restricted to the left hemisphere. Both patients performed poorly on the Warrington RMT, while ROC analyses of recognition for words, faces, and buildings indicated deficits in recollection and familiarity in both cases. If it is assumed that bilateral pathology is required to reveal clear deficits, then this pattern of results does not fit the predictions of Aggleton and Brown (1999), as patient 1 should show a selective loss of recollective-based recognition, while patient 2 should show a selective loss of familiarity information. The difficulty is that both cases have at least unilateral damage to thalamic nuclei or tracts in both of the putative systems (familiarity, recollection). It is also the case that unilateral 
thalamic damage can sometimes be sufficient to disrupt both verbal and nonverbal memory (e.g., Carlesimo et al. 2011; see also Baron et al. 1992). For these reasons, the observed pattern of findings (Cipolotti et al. 2008) need not be inconsistent with the model of Aggleton and Brown (1999).

In summary, current neuropsychological findings appear mixed over whether single-process or dual-process models best describe these clinical results. So far, there appear to be no diencephalic cases with a selective loss of familiarity processing, a result that would most clearly contradict single-process models. While studies of temporal lobe pathology have shown that such cases can exist (Bowles et al. 2007), they are exceptionally rare, and so the lack of any corresponding cases for the diencephalon (where the pathology is so rarely selective) may not be surprising. More compelling support for dual-process models comes from the finding that patients with marked mammillary body atrophy show matching levels of recognition to those with more subtle mammillary atrophy, yet only the former group suffers impaired recollection (Tsivilis et al. 2008; see also Carlesimo et al. 2007; Vann et al. 2009a, b). The critical point is that single-process models predict that recognition and recall losses should go hand-in-hand, i.e., not be dissociated. At the same time, the specific prediction that the medial dorsal thalamic nucleus is selectively vital for familiarity (Aggleton and Brown 1999) has failed to receive direct clinical support.

Finally, there is an alternative dual-process model that fits many of the clinical findings described above. In this hybrid model, familiarity and recollective processes are separate, but signals of familiarity can sometimes influence recollective processes, e.g., to enhance the learning of novel events (Fernandez and Tendolkur 2006; Albasser et al. 2010). In this model, a selective loss of recollection is possible as (1) the link between familiarity and recall is not obligatory and (2) recollection does not moderate familiarity, i.e., the relationship is one-way. Such a model would help to explain why it has proved possible to find diencephalic cases with a selective loss of recall but not a selective loss of familiarity (since recall is affected indirectly). While plausible, this model is not favored by structural equation modeling analyses (Quamme et al. 2004; Vann et al. 2009a,b); it fails to explain the double dissociations found after different medial thalamic lesions in animals (see below) and cannot explain how patients might show a selective loss of familiarity-based recognition alongside spared recall (Bowles et al. 2007).

\section{Brain imaging studies}

Surprisingly few functional MRI studies of normal participants have reported diencephalic changes associated with recognition memory, one problem being the need to resolve the signal from individual nuclei. One exception had participants rate how familiar previously presented scenes felt (Montaldi et al. 2006). As the subjective strength of familiarity for scene recognition increased, so activity declined linearly in the perirhinal cortex, insula, and left superior temporal cortex. The opposite relationship, i.e., increased activity with increased familiarity, was found in the left medial dorsal thalamic nucleus, the left ventrolateral and anteromedial frontal cortex, the posterior cingulate cortex, and left parietal cortex (Montaldi et al. 2006). Intriguing aspects of these results include the link between the medial dorsal nucleus and familiarity and the common pattern of changes in the medial dorsal nucleus and those cortical areas connected to this thalamic nucleus.

A different approach has been to use imaging techniques to examine patients with diencephalic pathology. Measures of metabolic imaging, e.g., positron emission tomography (PET) and spectrosocopy, have repeatedly demonstrated how thalamic strokes can cause long-lasting cortical hypoactivity (Baron et al. 1986; Fazio et al. 1992; Levasseur et al. 1992; Pepin and Auray-Pepin 1993; Clarke et al. 1994; Daum and Ackermann 1994; Van der Werf et al. 1999). These distal changes provide evidence of cortical diaschisis (Baron et al. 1986; Finger et al. 2004; Van der Werf et al. 1999, 2002). Closely related studies of the alcoholic Korsakoff's syndrome have also found extensive cortical hypoactivity (Fazio et al. 1992; Joyce et al. 1994; Paller et al. 1997; Reed et al. 2003). At least one study has scanned an amnesic Korsakoff patient during face encoding and face recognition (Caulo et al. 2005). Both hippocampal and ventrolateral prefrontal cortex activations were reduced, while dorsolateral prefrontal activity was preserved. Taken together, these studies show that, in order to understand why thalamic pathology might disrupt recognition, it is important to consider these indirect effects upon cortical sites.

\section{Findings from animal studies}

Studies of nonhuman primates have often relied on the delayed nonmatching-to-sample (DNMS) task (Mishkin and Delacour 1975). Here, monkeys typically select between two objects, one novel and one made familiar by its recent presentation to the monkey. Selection of the novel object (nonmatching) is rewarded. The objects are often then discarded and not used in later trials, so the stimuli are sometimes called "trial-unique." The face validity of such tasks is supported by the poor performance of Korsakoff amnesics given closely analogous, forced-choice recognition tests with trial-unique stimuli (Aggleton et al. 1988).

While a small number of rodent studies have used DNMS procedures for object recognition (Aggleton 1985), it is now more common to rely on the spontaneous differential exploration of novel vs. familiar stimuli (Ennaceur and Delacour 1988). The spontaneous object recognition (SOR) task is simple to run, requires no rule learning, and lends itself to numerous variants that can be used to assess associative recognition and recency (Ennaceur et al. 1997; Dix and Aggleton 1999; Warburton and Brown 2010). Procedurally, the spontaneous exploration task appears very similar to preferred-viewing tests given to humans, which are thought to tax processes required for explicit tests of recognition memory (Manns et al. 2000). The situation is, however, complicated by evidence that implicit processes can sometimes contribute to human recognition (e.g., Voss and Paller 2009), and it is unclear whether such processes might be involved in animal SOR tasks. A further limitation is that it is difficult with animals to isolate those cognitive processes that might contribute to explicit human recognition memory, i.e., familiarity and recollection. Even so, important behavioral advances have been achieved in trying to separate these processes in rats (Sauvage et al. 2008, 2010), though they have yet to be applied to the diencephalon.

\section{Nonhuman primates}

Diencephalic lesion studies with nonhuman primates have exclusively used Old World monkeys, in particular rhesus (Macaca mulatta) or cynomolgus (Macaca fascicularis) macaques. Current information is confined to tests of visual recognition memory, which have used DNMS or DMS (delayed matching-to-sample) procedures.

The first demonstration of a recognition (DNMS) deficit in a monkey with a diencephalic lesion (Aggleton and Mishkin 1983b) occurred after removal of all of the medial and midline thalamic nuclei, including the medial (magnocellular) part of the medial dorsal thalamic nucleus and much of the anterior thalamic nuclei (with some sparing of the anterior ventral nucleus). The loss of 
these combined nuclei was sufficient to induce a severe deficit, both in relearning DNMS and subsequent DNMS performance with increasing retention delays (Fig. 4, group MT). There was no obvious recovery of function (Aggleton and Mishkin 1983b). Follow-up experiments (Aggleton and Mishkin 1983a) revealed that subdividing this extensive medial thalamic lesion into an anterior division (centered on the anterior thalamic nuclei and rostral midline nuclei) (Fig. 4, group Ath) and a posterior division (centered on the medial dorsal nucleus and caudal midline nuclei) (Fig. 4, group Pth) produced DNMS deficits that were similar to one another but not as severe as those found with the larger, combined lesion (Fig. 4, Ath vs. Pth), i.e., both anterior and posterior medial thalamic damage contributed to the overall recognition memory deficit.

One concern is that the surgical approach for these thalamic lesions required a sagittal split of the fornix (Aggleton and Mishkin 1983a,b). A single control animal in which the fornix was split sagittally and the midline thalamic tissue removed along the rostro-caudal length of the thalamus was, therefore, examined. This monkey showed unaffected DNMS performance (Aggleton and Mishkin 1983a). A further concern is that both the extensive medial thalamic surgeries (anterior + posterior medial thalamus) and the anterior medial thalamic surgeries cut the mammillothalamic tract, resulting in atrophy of the mammillary bodies. It is, therefore, possible that dysfunction in the mammillary bodies contributed to the recognition deficits. This possibility was tested by (1) cutting the mammillothalamic tract in one monkey and (2) testing the impact of radiofrequency mammillary body lesions on DNMS. Both studies (Aggleton and Mishkin 1983a, 1985) found only mild DNMS deficits, far less severe than those seen after extensive medial thalamic lesions (Fig. 4).

Experiments by other laboratories have replicated the more selective diencephalic lesion effects described above. Radiofrequency lesions of the mammillary bodies in two cynomolgus monkeys produced an initial, mild DNMS deficit (Zola-Morgan et al. 1989), though the animals later returned to normal levels of recognition performance when retested 2 yr later. Likewise, mammillary body lesions produced mild but significant

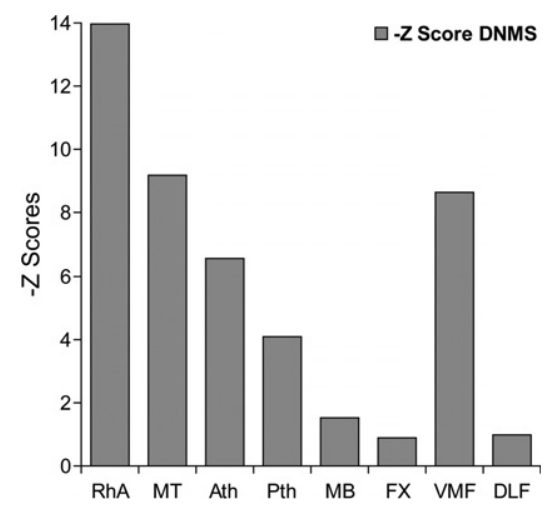

Figure 4. Delayed nonmatching-to-sample (DNMS) performance of cynomolgus monkeys with surgical lesions of the rhinal sulcus plus amygdala (RhA), medial thalamus (MT, i.e., Ath plus Pth), anterior medial thalamus (Ath), posterior medial thalamus (Pth), mammillary bodies (MB), fornix (FX), ventromedial prefrontal cortex (VMF), and dorsolateral prefrontal cortex (DLF). Performance is represented as the $Z$ score difference from the normal control group in each study. In all cases, the graphs depict mean performance over three retention delays $(30 \mathrm{sec}, 60 \mathrm{sec}$, $120 \mathrm{sec}$ ). All $Z$ scores are worse than the controls, i.e., all are $-Z$ scores. Data are only taken from studies using very similar training and testing methods (Aggleton and Mishkin 1983a,b, 1985; Bachevalier et al. 1985a; Bachevalier and Mishkin 1986; Murray and Mishkin 1986). recognition deficits in a study that also examined the effects of combined mammillary body and fornix lesions (Saunders 1983). There were no additive effects of fornix lesions upon mammillary body damage for object recognition (Saunders 1983).

Lesions of the medial dorsal thalamic nucleus (magnocellular plus parvocellular divisions) in cynomolgus monkeys that spared the anterior thalamic nuclei (Zola-Morgan and Squire 1985) delayed re-acquisition of the DNMS task. Subsequent testing with longer retention intervals (up to $10 \mathrm{~min}$ ) revealed a modest but clear-cut deficit in recognition memory. Aspiration lesions of just the medial part (magnocellular) of the medial dorsal thalamic nucleus (Parker et al. 1997) also revealed a mild deficit on trial-unique delayed matching-to-sample (DMS), though it was less severe than that observed after medial temporal (rhinal cortex) lesions. Finally, recording studies have found units in the medial dorsal and midline thalamus that reduce their firing rates with repetition of the same visual stimulus (Fahy et al. 1993), though the proportions of such units are small.

The medial dorsal thalamic nucleus has very extensive, reciprocal connections with the prefrontal cortex, with the magnocellular division connected with orbital and medial prefrontal areas (Fig. 1; Ray and Price 1993). This arrangement is notable, as removal of the medial and orbital prefrontal cortices induces severe DNMS deficits in monkeys (Fig. 4, group VMF), while dorsolateral prefrontal cortex removal (Fig. 4, DLF) has no apparent effect (Bachevalier and Mishkin 1986). One interpretation is that both the perirhinal cortex and the medial dorsal nucleus project to a common cortical site (the medial and orbital prefrontal cortex) with which they must interact to enable recognition memory. This view receives support from a crossed-lesion disconnection study that combined a unilateral lesion of the magnocellular medial dorsal nucleus with a unilateral perirhinal cortex lesion in the contralateral hemisphere, the combined surgery impairing DMS performance (Parker and Gaffan 1998).

Brief mention should also be made of the impact of fornix lesions in monkeys on DNMS and DMS performance. This tract provides the major route from the hippocampal formation to the medial diencephalon. The various studies have reported either mild impairments (e.g., Saunders 1983; Gaffan 1994a), or no apparent deficit (e.g., Bachevalier et al. 1985a,b; Zola-Morgan et al. 1989; Charles et al. 2004) following fornix lesions. It is evident (Fig. 4) that fornix transection does not produce the severe deficits in DNMS performance seen after extensive medial diencephalic lesions (Aggleton and Mishkin 1983b). This conclusion is reinforced by making comparisons with the studies by Bachevalier et al. (1985a,b), studies that used exactly the same methodology and the same pool of objects as used for the diencephalic lesions studies (see Fig. 4). There is, however, recent evidence that fornix damage can disrupt recency discriminations more than recognition (Charles et al. 2004). This result seems to accord with the observation that fornix deficits on DNMS/DMS appear when the pool of test objects is fewer than 400, leading to the repeated presentation of some objects across sessions (Owen and Butler 1984; Charles et al. 2004). This result can be contrasted with the impact of medial dorsal thalamic lesions, where the DMS deficit can disappear when repeated small-set sizes are used (Parker et al. 1997).

The consensus is that focal damage within the monkey medial diencephalon can impair visual recognition memory, but that major deficits emerge only when multiple medial diencephalic nuclei are damaged, i.e., the lesion effects appear additive. Both single-process and dual-process models can accommodate these results. A further problem is that the surgical techniques used in these studies damage fibers of passage, making interpretation more difficult. Next, we consider rodent studies, where it should be possible to make more selective lesions. 


\section{Rodents}

Most rodent studies have used the spontaneous object recognition task (SOR), though a few have trained rats on DNMS tasks. This section will largely ignore tests of spatial recognition and spatial recency, even though numerous studies have described the effects of diencephalic lesions on such tasks, e.g., T-maze alternation and radial-arm maze foraging. One reason for excluding these studies is the considerable amount of evidence that the rodent mammillary bodies and the anterior thalamic nuclei are particularly important for spatial and navigational processes, and so any observed deficits need not reflect recognition impairments per se. A further reason is that spatial tests very rarely involve truly novel spatial stimuli; the large majority tax relative recency decisions, e.g., T-maze alternation and radial-arm maze tests.

\section{Mammillary bodies}

Both tests of object recognition using DNMS (Aggleton et al. 1990) and SOR (Aggleton et al. 1995) have failed to find evidence that mammillary body lesions in rats disrupt performance. As the SOR task only used retention intervals of up to $15 \mathrm{~min}$ between sample and test phase, there remains the possibility that recognition deficits might still emerge after longer retention intervals.

Research investigating nonspatial recency judgments following lesions to the mammillary bodies has been limited. Using a DNMS task (Aggleton et al. 1990), the effects of mammillary body damage on object recency discriminations were examined by repeating a list of just four pairs of distinct goal boxes. The ability of rats with mammillary body lesions to make relative recency discriminations appeared unaffected. Similarly, Sziklas and Petrides (1993) found that mammillary body lesions did not impair a DNMS task where the rats had to chose repeatedly between white or black arms of a modified plus maze.

\section{Anterior thalamic nuclei}

It has repeatedly been found that lesions of the anterior thalamic nuclei do not affect standard SOR tasks (Aggleton et al. 1995; Warburton and Aggleton 1999; Wilton et al. 2001; Moran and Dalrymple-Alford 2003; Mitchell and Dalrymple-Alford 2005), nor do they affect novel odor detection (Wolff et al. 2006). In the SOR studies, the retention delays have been extended up to $120 \mathrm{~min}$, but no evidence has emerged of a time-dependent deficit. This null result is still found when the anterior thalamic lesions extend caudally to involve large portions of the medial dorsal thalamic nucleus (Warburton and Aggleton 1999).

The lack of any object recognition deficit after anterior thalamic lesions has led researchers to challenge these rats with variants of the standard object recognition task. In one study, rats were given stimuli to recognize that were either small complex objects or much larger painted boxes (Warburton and Aggleton 1999). The rationale arose from evidence that rats with fornix lesions are selectively impaired with the latter (larger) stimuli (Cassaday and Rawlins 1995). Again, no lesion-induced deficit was found after anterior thalamic lesions. In contrast, anterior thalamic lesions, which included the lateral dorsal nucleus, did impair object-in-place recognition (Wilton et al. 2001), a test of associative recognition where the object is familiar, but its location is novel (Dix and Aggleton 1999). This deficit is consistent with the many other studies demonstrating the importance of the anterior thalamic nuclei for tests of spatial learning and memory that are also sensitive to hippocampal damage.

The impact of anterior thalamic lesions on recency discrimination has also been explored. Comparisons between two objects, one presented $2 \mathrm{~h}$ previously, the other presented $1 \mathrm{~h}$ previously, found a normal preference for the older object after anterior thalamic lesions (Mitchell and Dalrymple-Alford 2005). In contrast, Wolff et al. (2006) reported that rats with anterior thalamic lesions were impaired at discriminating the temporal order of odors. There are numerous differences in the procedures used to examine object and odor recency, including task difficulty, the requirement to learn a reinforced rule (only in the olfactory task), and the intervals between the recent and less recent stimuli. Consequently, there is a need to re-examine the importance of the anterior thalamic nuclei for object recency.

\section{Fornix}

Numerous studies have examined the effects of fornix lesions in rats on object recognition using DNMS (Aggleton et al. 1990) or SOR (e.g., Aggleton et al. 1995; Ennaceur and Aggleton 1997; Ennaceur et al. 1996, 1997; Warburton and Aggleton 1999; Bussey et al. 2000; Clark et al. 2000; Warburton et al. 2000) and consistently found no lesion-induced deficits. In contrast, objectlocation recognition (detecting that an object occupies a novel location) is impaired after fornix lesions (Ennaceur et al. 1997; Bussey et al. 2000; Warburton et al. 2000). Furthermore, a study using crossed unilateral lesions showed that fornix connections function together with the anterior thalamic nuclei to support this object-location task (Warburton et al. 2000).

\section{Medial dorsal thalamic nucleus}

Lesions in the medial dorsal thalamic nucleus in rats have different effects depending on the task used. Rats with cytotoxic medial dorsal lesions were impaired on acquisition of a DNMS task with object stimuli (Hunt and Aggleton 1991), but those rats that acquired the task showed normal performance over retention intervals of up to $60 \mathrm{~s}$. A separate study examined the effects of bilateral electrolytic medial dorsal lesions on DNMS performance (Mumby et al. 1993). Many of the rats with medial dorsal lesions showed a severe deficit in either acquiring or re-acquiring the DNMS task after surgery. There was inconsistent evidence of a delay-dependent impairment (Mumby et al. 1993). The results suggest that a major effect of medial dorsal lesions is not on object recognition per se but rather on other aspects of task acquisition and performance, such as sensitivity to the reinforcement contingency (McAlonan et al. 1993; Mitchell et al. 2007).

The resulting prediction is that medial dorsal thalamic lesions should have little or no impact on SOR tests (where there is no specific rule training or reinforcement contingency). This prediction is supported by an SOR study that used retention delays of up to 60 min (Hunt and Aggleton (1998a). Likewise, Mitchell and Dalrymple-Alford (2005) found no evidence that medial dorsal thalamic lesions disrupted SOR, though their rats were significantly impaired at performing recency discriminations. Following from these two SOR studies, Cross et al. (2010) further examined the role of this nucleus in recognition memory. Rats were tested on various aspects of recognition memory: standard object novelty; temporal order (recency); object-in-place recognition (the ability to detect the re-location of a particular object); and object-location recognition (the ability to detect the movement of any object to a novel location). Consistent with previous reports (Hunt and Aggleton 1998a; Mitchell and DalrympleAlford 2005), there was no effect of bilateral medial dorsal thalamic lesions on either novel object recognition or object-location recognition (Cross et al. 2010). Lesion-induced deficits were, however, found for object-in-place memory (a test of associative recognition) and temporal order (recency) memory. This pattern of deficits matches that seen after medial prefrontal cortex lesions in rats (Barker et al. 2007). 
In summary, lesions of the medial dorsal thalamic nucleus in rats can disrupt tests of object recognition, but there is little evidence for a specific loss of recognition memory. More consistent deficits have been found for object recency, and these may reflect the very close functional links between this nucleus and the prefrontal cortex (Hunt and Aggleton 1998b; Barker et al. 2007).

\section{Intralaminar thalamic nuclei}

As already noted, the connections of the midline and intralaminar nuclei clearly suggest an involvement in cognition. In the rat brain, some of these nuclei have very widespread cortical connections (e.g., rhomboid nucleus, central medial nucleus, parafascicular nucleus), while others are more specifically linked with the prefrontal cortex (parataenial nucleus, reuniens nucleus) and the posterior cingulate region (paracentral nucleus, reuniens nucleus) (Groenewegen and Berendse 1994; Van der Werf et al. 2002). Based on their connectivity, Van der Werf et al. (2002) has identified four groups of intralaminar and midline nuclei: (1) a dorsal group, (paraventricular and parataenial) with potential viscerolimbic functions; (2) a lateral group (central lateral, paracentral, and rostral central medial) with potential cognitive functions; (3) a ventral group (reuniens and rhomboid) potentially involved in multimodal sensory processing; and (4) a posterior group (posterior central medial and parafascicular) potentially involved in limbic motor functions.

In an attempt to test the prediction that the lateral group of nuclei is particularly important for cognitive functions, Mitchell and Dalrymple-Alford (2005) compared the effects of lesions in either the lateral intralaminar group (including the lateral part of the medial dorsal nucleus), the medial dorsal nucleus (its medial and central divisions), or the anterior thalamic nuclei. All three lesion groups showed intact spontaneous object recognition (15 min retention), but recency deficits were found in the groups with medial dorsal lesions and lateral intralaminar lesions.

Other evidence that the lateral intralaminar nuclei might contribute to aspects of recognition memory comes from stimulation studies. Appropriate electrical stimulation of the central lateral nucleus can facilitate spontaneous object recognition (Shrivalkar et al. 2006). This facilitation occurred when stimulation was applied during recognition testing but not during the sample period or during the retention interval. A separate study showing that stimulation of the rostral intralaminar nuclei can enhance delayed matching-to-position performance in an automated apparatus (Mair and Hembrook 2008) points to a possible role in recency judgments.

\section{Toward a model of diencephalic contributions to recognition memory}

Numerous clinical and animal studies have demonstrated the critical involvement of the medial temporal lobe for recognition memory, presumably arising from the region's close connectivity with convergent sensory information from cortical association areas. This arrangement ensures that medial temporal structures such as the perirhinal cortex and hippocampus are ideally placed to detect rapidly the repeat occurrence of an event and then initiate appropriate brain responses (Brown and Aggleton 2001; Diana et al. 2007; Eichenbaum et al. 2007; Squire et al. 2007). Once the medial temporal lobe has performed this function, why should additional, diencephalic nuclei be required for the same cognitive task? The notion of simply providing a relay to further sites is contrary to current views of the thalamic function (e.g., Sherman 2007; Tsanov et al. 2011) and looks most unlikely, given that the medial temporal lobe already has direct connections to sites such as the prefrontal and cingulate cortices (Aggleton and Brown 2006), i.e., those sites that might be the target of a thalamic relay. Any explanation must, therefore, depend on additional information or additional processing provided by the diencephalon that other regions lack. Integral aspects of this assumption concern the direct, reciprocal interconnections between the medial diencephalon and the medial temporal lobe. It is, however, also necessary to consider the interactions between medial temporal lobe efferents and medial diencephalic efferents on shared targets, likely sites being within the prefrontal and cingulate cortices.

Given these assumptions it is highly significant that within the diencephalon only the anterior thalamic nuclei and some midline nuclei have direct, reciprocal connections with the hippocampal formation and the entorhinal cortices (Fig. 1; Amaral and Cowan 1980; DeVito 1980; Aggleton et al. 1986; Saunders et al. 2005). Processes that these thalamic nuclei could bring to these medial temporal lobe sites include theta regulation and navigational information, along with the integration of subicular, prefrontal, and mammillary body connections (Vertes et al. 2004; Aggleton et al. 2010; Wright et al. 2010; Tsanov et al. 2011). As part of this latter process, there are tegmental inputs to the anterior thalamic nuclei that contribute to mnemonic processing (Mitchell et al. 2002; Vann 2009) but rely on the diencephalon to reach the medial temporal lobe.

The connectivity of the medial dorsal nucleus is very different. This nucleus receives inputs from the perirhinal and entorhinal cortices but does not project back to medial temporal lobe sites (Fig. 1). The implication is that the principal contributions of the medial dorsal nucleus to recognition memory reflect its prefrontal connections (Parker and Gaffan 1998) and their integration with its direct inputs from the medial temporal lobe. A third pattern of connections is found for the intralaminar nuclei as they receive few, if any, hippocampal or parahippocampal inputs but do project to multiple cortical areas. Consequently, three groupings of thalamic nuclei can be distinguished, each with different connectivities: Group 1-anterior thalamic nuclei plus some midline nuclei; Group 2-medial dorsal nucleus; and Group 3-intralaminar nuclei.

A further consideration of these patterns of connectivity may also help to explain why DNMS deficits are seen in monkeys after medial diencephalic lesions, yet such lesions in rats typically spare behavioral tests of object recognition. This null effect in rodents is seen even when multiple nuclei are involved in the same surgery (e.g., Warburton and Aggleton 1999; Mitchell and DalrympleAlford 2005). One possibility is that these species differences reflect the ways that the medial temporal lobe interacts with the medial diencephalon. In the rat, unlike the monkey, structures such as the medial dorsal nucleus receive few, if any, projections from the perirhinal cortex (Groenewegen 1988). If the rat is predominantly reliant on perirhinal familiarity-based processes for standard tests of object recognition, then it is likely that temporal lobe functions are largely sufficient (Mumby and Pinel 1994; Albasser et al. 2009, 2010), as the rat perirhinal cortex cannot access the medial diencephalon. Consistent with this interpretation, immediate-early gene imaging studies have found increased c-fos activity for novel visual stimuli in the perirhinal cortex but not in the medial dorsal thalamic nucleus (Zhu et al. 1995). Likewise, the rat perirhinal cortex does not appear to require interactions with the prefrontal cortex for object recognition (Warburton and Brown 2010), yet perirhinal-prefrontal interactions are required in the monkey (Parker and Gaffan 1998). The lack of importance of the rat prefrontal cortex for object recognition memory (in contrast to primates) removes another potential mode of medial diencephalic action in rodents, i.e., interactions with prefrontal cortex. The situation for object recency and 


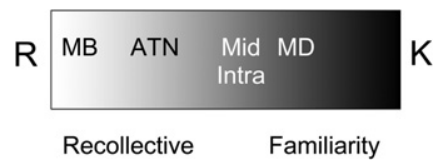

Figure 5. Schematic showing the proposed balance of action from diencephalic nuclei upon two independent components of recognition memory-recollective-based recognition (R) and familiarity-based recognition (K). The gradation from white $(R)$ to black $(K)$ is used to represent the relative involvement of the various diencephalic nuclei with these two information types. With the exception of the mammillary bodies, it seems unlikely that any other region has a purely selective effect on either R or K. Abbreviations: ATN, anterior thalamic nuclei; Intra, intralaminar thalamic nuclei; MB, mammillary bodies; MD, medial dorsal thalamic nucleus; Mid, midline thalamic nuclei.

some forms of associative recognition appears quite different, as now the prefrontal cortex has a vital role in the rat brain, along with the medial diencephalon (Warburton and Brown 2010).

Drawing together the various strands of evidence, we propose a MEMN model to explain why the human diencephalon is important for recognition memory (Fig. 5). To understand the rationale for this model, it is helpful to summarize the answers to a number of critical questions:

1. Is damage to one diencephalic nucleus sufficient to produce the severe recognition deficits sometimes seen after medial diencephalic pathology?

Both clinical and animal studies repeatedly give the same result: No individual diencephalic nucleus can account for the severe recognition deficits often associated with pathology in this region. The results from studies with monkeys consistently show that, as lesions become increasingly specific, the extent of any recognition deficit diminishes.

2. Is damage to one diencephalic nucleus necessary to produce the recognition deficits sometimes seen after medial diencephalic pathology?

Evidence suggests that all of the principal nuclei (or nuclear groups) under consideration (the mammillary bodies, the anterior thalamic nuclei, the medial dorsal nucleus, the intralaminar nuclei, and the midline nuclei) can contribute to recognition memory. The repeated finding that the integrity of the mammillary body-mammillothalamic tract-anterior thalamic group is necessary for episodic memory (Vann and Aggleton 2004) might, at first, imply that damage to any one of these three structures is a necessary pre-condition for a consistent recognition memory loss, although it need not be sufficient (e.g., Graff-Radford et al. 1990). As already described, however, there is evidence that pathology in more caudal thalamic nuclei can also impair recognition (e.g., Isaac et al. 1998; Zoppelt et al. 2003; Gold and Squire 2006; Soei et al. 2008). Because of the route of most fiber tracts to and from the anterior thalamic nuclei, it is unlikely that these more caudal thalamic pathologies will have disconnected the anterior thalamic group, i.e., had hidden effects upon these more rostral nuclei. The conclusion is, therefore, that these more caudal thalamic nuclei can impact upon recognition. It seems unlikely that damage to one specific nucleus is a requirement.

3. Under what circumstances does diencephalic pathology cause severe recognition memory deficits?

Some diencephalic amnesics show exceptionally poor recognition memory (Aggleton and Shaw 1996). Such cases invariably have damage to multiple nuclei within the medial diencephalon. The effective pathology in many of these cases almost certainly includes the impact of tract damage within the thalamus, e.g., to the mammillothalamic tract and inferior thalamic peduncle (Graff-Radford et al. 1990), as well as to fibers passing to and from the prefrontal cortex (Pepin and Auray-Pepin 1993). Some cases with the poorest recognition memory are those with Korsakoff's syndrome. In this disorder, there is often both cell loss in multiple diencephalic sites and extensive cortical dysfunction (e.g., Kopelman et al. 2009).

4. Can recognition be spared when recall is impaired?

Despite difficulties in comparing levels of performance, there is now convincing evidence from both single and group studies that, occasionally, recall can be severely compromised, while recognition is apparently spared. The clearest evidence relates to studies of mammillary body dysfunction (e.g., Dusoir et al. 1990; Hildebrandt et al. 2001; Carlesimo et al. 2007; Tsivilis et al. 2008) and includes findings from the Doors and People Test (e.g., Tsivilis et al. 2008), which specifically attempts to equate task difficulty (Baddeley et al. 1994). Consequently, any account of diencephalic mechanisms supporting recognition memory must be able to explain this asymmetric relationship. As already explained, this dissociation poses problems for single-process models of recognition memory (Squire et al. 2007).

5. Do different diencephalic sites make qualitatively different contributions to recognition memory?

There are very good reasons to suppose that the principal nuclear groups under investigation have quite different functions. These reasons include: (1) their unique patterns of connectivity with medial temporal sites (Fig. 1); (2) the lack of intra-thalamic connections between the principal nuclei, so that they can act in a largely independent manner (a situation strikingly different to that in the medial temporal lobe, where all structures are interconnected); and (3) the number of dissociations between the consequences of selective lesions in these diencephalic nuclei in animals. Examples of double dissociations between the effects of anterior thalamic lesions and medial dorsal thalamic lesions can be seen in different domains of spatial learning as well as perseverative behavior (e.g., Aggleton et al. 1995; Hunt and Aggleton 1998b; Chudasama et al. 2001; Mitchell and Dalrymple-Alford 2006; Wolff et al. 2008). Likewise, there are double dissociations between the impact of anterior thalamic lesions and lateral intralaminar thalamic lesions on different classes of spatial memory task (Mitchell and Dalrymple-Alford 2005; Wolff et al. 2008). While all of these examples point to different contributions to cognition, they do not prove that these differences include recognition. There do, however, appear to be potential double-dissociations within associative recognition. One example involves the respective effects in rats of anterior thalamic lesions and medial dorsal thalamic lesions on object-in-place recognition and object recency (Wilton et al. 2001; Mitchell and Dalrymple-Alford 2005; Cross et al. 2010). Another example comes from studies with monkeys where reducing set size, i.e., repeating objects during DMS testing, might have opposite effects on medial dorsal lesions and fornix lesions (Owen and Butler 1984; Parker et al. 1997; Charles et al. 2004). The implication is that some sites have qualitatively different roles regarding recognition.

As noted above, the nuclei of interest have individual patterns of connectivity and may be placed into at least three different groupings. A key aspect of these groupings concerns the origins of the medial temporal lobe projections to the diencephalon. The primate anterior thalamic nuclei, mammillary bodies, and midline thalamic nuclei all receive extensive direct inputs from the hippocampus (subiculum), but the intralaminar nuclei and the medial dorsal nucleus receive few, if any, such inputs (Aggleton et al. 1986; Saunders et al. 2005). In contrast, only the 
medial dorsal nucleus (magnocellular part) and some midline nuclei appear to receive direct inputs from the perirhinal cortex (Aggleton and Mishkin 1984; Russchen et al. 1987; Gower 1989). These differences are potentially most important as both the perirhinal cortex and the hippocampus are key sites within the medial temporal lobe for recognition, but there is also much evidence that these two temporal sites make qualitatively different contributions to recognition memory (Murray and Mishkin 1998; Aggleton and Brown 1999, 2006; Brown and Aggleton 2001; Bowles et al. 2007; Diana et al. 2007; Eichenbaum et al. 2007; but see Squire et al. 2007). Much of this evidence indicates that the perirhinal cortex is vital for familiarity information, while the hippocampus is required for recollective information (Brown and Aggleton 2001; Bowles et al. 2007; Diana et al. 2007; Eichenbaum et al. 2007).

\section{Toward a new model of diencephalic recognition memory processes and} an explanation for the patterns of deficits observed after diencephalic damage The MEMN model supposes that there are at least three different ways in which the medial diencephalon supports recognition. In addition, there is a further mechanism by which diencephalic pathology can disrupt recognition memory. The impact of any given diencephalic lesion will reflect the additive disruption of these processes (Fig. 5).

The MEMN model builds on the proposal of Aggleton and Brown (1999) who supposed that the mammillary body-anterior thalamic nuclear grouping is vital for recollective-based recognition, while the medial dorsal thalamic nucleus is vital for familiarity-based recognition. Their model also supposed that, because these are two independent processes, the loss of just one of these systems can be compensated for by the other. It is also assumed that animal tests of recognition memory predominantly test familiarity-based recognition and that to reveal an involvement in recollective-based recognition it may be more appropriate to look at rather different aspects of learning and memory, e.g., contextual learning and spatial learning (Gaffan 1994b; Aggleton and Pearce 2001). These latter forms of learning are conjointly dependent on the hippocampus and the anterior thalamic nuclei (Parker and Gaffan 1997a,b; Warburton et al. 2001).

As already described, the proposal that the mammillary body-anterior thalamic grouping is vital for recollective-based recognition has received clear clinical support (Dusoir et al. 1990; Carlesimo et al. 2007; Tsivilis et al. 2008; Vann et al. 2009a,b). While these particular clinical studies focus on the mammillary bodies, the exceptionally dense projections from the mammillary bodies to the anterior thalamic nuclei must surely mean that these thalamic nuclei are also vital for recollective-based recognition. Unlike the mammillary bodies, the anterior thalamic nuclei do have appreciable reciprocal interactions with medial prefrontal and cingulate cortices. While these cortical interactions are presumably important for recollective-based recognition (Simons and Spiers 2003; Vann et al. 2009a,b), they also create the potential for an additional anterior thalamic contribution to familiarity-based recognition.

The proposal that the medial dorsal nucleus has a specific contribution to familiarity-based recognition (Aggleton and Brown 1999) remains unproven. Support comes from the presence of perirhinal cortex projections to the magnocellular portion of this nucleus (Aggleton and Mishkin 1984; Russchen and Amaral 1987), these inputs being noteworthy as many models assume that the perirhinal cortex provides familiarity information (e.g., Brown and Aggleton 2001; Eichenbaum et al. 2007). There is also fMRI evidence that activity in the medial dorsal nucleus correlates positively with perceptions of the strength of familiarity (Montaldi et al. 2006). Studies with monkeys have also found single units in the medial dorsal nucleus that reduce their firing with repetition of a visual stimulus (Fahy et al. 1993), while removal of the magnocellular medial dorsal nucleus is sufficient to induce a mild recognition deficit (Parker et al. 1997; see also Aggleton and Mishkin 1983a; Zola-Morgan and Squire 1985). As noted above, the anatomy of this nucleus suggests that the key connections are its inputs from the perirhinal and entorhinal cortices and its efferents to the medial and orbital prefrontal cortex (Bachevalier and Mishkin 1986; Parker and Gaffan 1998).

The principal limitation is that clinical studies have failed to find evidence for a selective loss of familiarity-based recognition following damage to the medial dorsal nucleus (e.g., Zoppelt et al. 2003; Cipolotti et al. 2008; Soei et al. 2008). Instead, clinical studies more often suggest that medial dorsal thalamic damage can induce frontal cortex-like deficits, e.g., in executive function (Van der Werf et al. 2002, 2003a,b). This problem is compounded by the fact that the effects of selective medial dorsal thalamic nucleus pathology in humans probably have yet to be examined, given the likelihood of tract damage and the involvement of the adjacent intralaminar and midline nuclei. Given the frontal connectivity of the medial dorsal nucleus and the need within dual-process models for a system that supports familiarity-based recognition, the MEMN model assumes that the medial dorsal nucleus has a key role for this form of information. For reasons explained below, this role may not always be apparent following damage to this nucleus.

The MEMN model includes two further mechanisms that, when combined, will blur the distinctions between familiarity and recollective processes. The first is that the intralaminar and midline thalamic nuclei (the "nonspecific" thalamic nuclei) are assumed to influence a wide array of cognitive processes, including recognition, by their modulatory influences on arousal and attention (Groenewegen and Berendse 1994; Van der Werf et al. 2002). At present, we have little evidence to indicate whether the intralaminar/midline thalamic nuclei are particularly involved in recollective or familiarity processes. Answering this question is a demanding task, as the various nuclei have unique patterns of cortical and subcortical connections and so may have individual roles. For example, nucleus reuniens is likely to be more involved in recollective- than familiarity-based recognition in view of its hippocampal connections (Vertes et al. 2007), but this prediction remains to be tested.

A second mechanism again reflects the actions of thalamus pathology upon the cortex. As already noted, long-term decreases in cortical activity and blood flow can be caused by thalamic strokes (Baron et al. 1986, 1992; Fazio et al. 1992; Levasseur et al. 1992; Pepin and Auray-Pepin 1993) and by Korsakoff's syndrome (Fazio et al. 1992; Joyce et al. 1994; Paller et al. 1997; Reed et al. 2003). An intriguing discovery is that bilateral cortical hypoactivity can be seen after unilateral thalamic strokes (Baron et al. 1992). It is also known that unilateral strokes can sometimes affect both verbal and nonverbal memory (Carlesimo et al. 2011). The implication is that the neuropsychological impairments in such patients reflect their bilateral cortical changes (Baron et al. 1992). These diaschisis-like effects might be expected to be particularly pronounced across the medial and orbital prefrontal cortices (Pepin and Auray-Pepin 1993; Daum and Ackermann 1994; see also Parker and Gaffan 1998), given their close anatomical links with multiple medial diencephalic nuclei.

The same diaschisis-like mechanism is also likely to chronically disrupt the posterior cingulate cortex. This region not only has dense interconnections with the anterior thalamic nuclei but has also been repeatedly implicated in various aspects of memory (Vann et al. 2009b; Aggleton 2010). Evidence for posterior cingulate dysfunction after diencephalic injury comes from (1) the consistent reductions in posterior cingulate metabolic 
activity in diencephalic amnesia (Fazio et al. 1992; Joyce et al. 1994; Paller et al. 1997; Reed et al. 2003), (2) evidence that anterior thalamic strokes causing amnesia are sufficient to cause posterior cingulate hypoactivity (Clarke et al. 1994), and (3) studies with rats showing how selective anterior thalamic lesions and mammillothalamic tract lesions can markedly reduce immediate-early gene expression in the posterior cingulate (retrosplenial) cortex and hippocampus yet leave both structures seemingly intact (Jenkins et al. 2002, 2004; Poirier and Aggleton 2009; Vann and Albasser 2009). These distal activity changes do not merely reflect the loss of afferent stimulation; there are also subtle intrinsic changes to the cortex itself (Poirier et al. 2008). Slice recordings have, for example, shown a loss of some forms of plasticity in the retrosplenial cortex after anterior thalamic lesions in rats (Garden et al. 2009).

A consequence is that the thalamus can have both direct and indirect actions upon recognition memory (Fig. 5). The direct actions involve the integral contributions of the mammillary bodies-anterior thalamic nuclei to episodic memory (Aggleton et al. 2010) and, hence, recollective-based recognition. Likewise, the medial dorsal thalamic nucleus may prove to have a direct role in supporting familiarity information, presumably via its perirhinal and prefrontal connections. At the same time, the medial dorsal thalamic nucleus contributes to other aspects of cognition and so, along with the intralaminar/midline nuclei, can indirectly affect recognition. Finally, long-term cortical diaschisis following thalamic damage may add another tier of dysfunction. Of those vulnerable cortical sites, the most critical are assumed to be the prefrontal (medial and orbital) and cingulate regions. This cortical interference could then affect both recollective- and familiarity-based recognition. A potential problem is that this complex combination of effects makes it difficult to derive clear predictions regarding the cumulative effects of injury to multiple thalamic nuclei, so creating a risk of post-hoc accounts.

A final point concerns the potential involvement of a small number of other diencephalic nuclei in recognition memory that have not yet been discussed. Candidates include (1) the medial pulvinar nucleus, because of its dense inputs from medial temporal structures and sensory association cortex; (2) the reticular nucleus, because of its intra-thalamic connections; and (3) the ventral lateral thalamic nucleus, because of its apparent contribution to recognition loss after caudal thalamic injury (Zoppelt et al. 2003; Soei et al. 2008). At present, there is insufficient evidence to presume the importance of these other diencephalic nuclei, but the advent of better functional imaging may help to reveal the cortical-subcortical interplay that involves multiple groups of nuclei and contributes both directly and indirectly to recognition memory. In doing so, it should prove possible to test the MEMN model.

\section{Acknowledgments}

This work was supported by the Wellcome Trust (WT087855, J.P.A., E.C.W.; WT083361, J.R.D.), NSERC (J.R.D.); and ORSA (J.R.D.).

\section{References}

Aggleton JP. 1985. One trial object recognition by rats. Quart J Exp Psych 37B: $279-294$.

Aggleton JP. 2008. Understanding anterograde amnesia: Disconnections and hidden lesions. Quart J Exp Psych 61: 1441-1471.

Aggleton JP. 2010. Understanding retrosplenial amnesia: insights from animal studies. Neuropsychologia 48: 2328-2338.

Aggleton JP, Brown MW. 1999. Episodic memory, amnesia, and the hippocampal-anterior thalamic axis. Behav Brain Sci 22: 425-444.

Aggleton JP, Brown MW. 2006. Interleaving brain systems for episodic and recognition memory. Trends Cog Sci 10: 455-463.

Aggleton JP, Mishkin M. 1983a. Memory impairments following restricted medial thalamic lesions in monkeys. Exp Brain Res 52: 199-209.
Aggleton JP, Mishkin M. 1983b. Visual recognition impairment following medial thalamic lesions in monkeys. Neuropsychologia 21: 189-197.

Aggleton JP, Mishkin M. 1984. Projections of the amygdala to the thalamus in the cynomolgus monkey. J Comp Neurol 222: 56-68.

Aggleton JP, Mishkin M. 1985. Mamillary-body lesions and visual recognition in monkeys. Exp Brain Res 58: 190-197.

Aggleton JP, Pearce JM. 2001. Neural systems underlying episodic memory: Insights from animal research. Phil Trans Roy Soc (Lond) 356: $1467-1482$.

Aggleton JP, Sahgal A. 1993. The contribution of the anterior thalamic nuclei to anterograde amnesia. Neuropsychologia 31: 1001-1019.

Aggleton JP, Saunders RC. 1997. The relationships between temporal lobe and diencephalic structures implicated in anterograde amnesia. Memory 5: 49-71.

Aggleton JP, Shaw C. 1996. Amnesia and recognition memory: A reanalysis of psychometric data. Neuropsychologia 34: 51-62.

Aggleton JP, Desimone R, Mishkin M. 1986. The origin, course, and termination of the hippocampo-thalamic projections in the macaque. J Comp Neurol 243: 409-422.

Aggleton JP, Nicol RM, Huston AE, Fairbairn AF. 1988. The performance of amnesic subjects on tests of experimental amnesia in animals: Delayed matching-to-sample. Neuropsychologia 26: $265-272$.

Aggleton JP, Hunt PR, Shaw C. 1990. The effects of mammillary body and combined amygdalar-fornix lesions on tests of delayed nonmatching-to-sample. Behav Brain Res 40: 145-157.

Aggleton JP, Neave NJ, Nagle S, Hunt PR. 1995. A comparison of the effects of anterior thalamic, mamillary body and fornix lesions on reinforced spatial alternation. Behav Brain Res 68: 91-101.

Aggleton JP, McMackin D, Carpenter K, Hornak J, Kapur N, Halpin S, Wiles CM, Kamel H, Brennan P, Gaffan D. 2000. Differential effects of colloid cysts in the third ventricle that spare or compromise the fornix. Brain 123: 800-815.

Aggleton JP, O'Mara SM, Vann SD, Wright NF, Tsanov M, Erichsen JT. 2010. Hippocampal-anterior thalamic pathways for memory: Uncovering a network of direct and indirect actions. Eur J Neurosci 31: 2292-2307.

Albasser MM, Davies M, Futter JE, Aggleton JP. 2009. Magnitude of the object recognition deficit associated with perirhinal cortex damage in rats: Effects of varying the lesion extent and the duration of the sample period. Behav Neurosci 123: 115-124.

Albasser M, Poirier GL, Aggleton JP. 2010. Qualitatively different modes of perirhinal-hippocampal engagement when rats explore novel vs. familiar objects as revealed by c-fos imaging. Eur J Neurosci 31: $134-147$.

Amaral DG, Cowan WM. 1980. Subcortical afferents to the hippocampal formation in the monkey. J Comp Neurol 189: 573-591.

Bachevalier J, Mishkin M. 1986. Visual recognition impairment follows ventromedial but not dorsolateral prefrontal lesions in monkeys. Behav Brain Res 20: $249-261$.

Bachevalier J, Parkinson JK, Mishkin M. 1985a. Visual recognition in monkeys: Effects of separate vs. combined transection of fornix and amygdalofugal pathways. Exp Brain Res 57: 554-561.

Bachevalier J, Saunders RC, Mishkin M. 1985b. Visual recognition in monkeys: Effects of transection of fornix. Exp Brain Res 57: 547-553.

Baddeley A, Emslie H, Nimmo-Smith I. 1994. Doors and People. A test of visual and verbal recall and recognition. Thames Valley Test Company, Bury St Edmunds, England.

Barker GRI, Bird F, Alexander V, Warburton EC. 2007. Recognition memory for objects, place, and temporal order: A disconnection analysis of the role of the medial prefrontal cortex and perirhinal cortex. J Neurosci 27: 2948-2957.

Baron JC, D'Antona R, Pantano P, Serdaru M, Samson Y, Bousser MG. 1986. Effects of thalamic stroke on energy metabolism of the cerebral cortex. Brain 109: 1243-1259.

Baron JC, Levasseur M, Mazoyer B, Legault-Demare F, Mauguiere F, Pappata S, Jedynak P, Derome P, Cambier J, Tran-Dinh S. 1992. Thalamocortical diaschisis: Positron emission tomography in humans. J Neurol Neurosurg Psychiat 55: 935-942.

Beglinger LJ, Haut MW, Parsons MW. 2006. The role of the mammillary bodies in memory: A case of amnesia following bilateral resection. Eur J Psychiat 20: 88-95.

Bentivoglio M, Kultas-Ilinsky K, Ilinsky I. 1993. Limbic thalamus: Structure, intrinsic organization, and connections. In Neurobiology of the cingulate cortex and limbic thalamus (ed. BA Vogt, M Gabriel), pp. 71-122. Birkhauser, Boston, MA.

Berendse HW, Groenewegen HJ. 1991. Restricted cortical termination fields of the midline and intralaminar thalamic nuclei in the rat. Neuroscience 42: $73-102$.

Bowles B, Crupi C, Mirsattari SM, Pigott SE, Parrent AG, Pruessner JC, Yonelinas AP, Kohler S. 2007. Impaired familiarity with preserved recollection after anterior temporal-lobe resection that spares the hippocampus. Proc Natl Acad Sci 104: 16382-16387. 
Brown MW, Aggleton JP. 2001. Recognition memory: What are the roles of the perirhinal cortex and hippocampus? Nat Rev Neurosci 2: 51-61.

Bussey TJ, Duck JD, Muir JL, Aggleton JP. 2000. Distinct patterns of behavioral impairments resulting from fornix transection or neurotoxic lesions of the perirhinal and postrhinal cortices in the rat. Behav Brain Res 111: $187-202$.

Carlesimo GA, Serra L, Fadda L, Cherubini A, Bozzali M, Caltagirone C. 2007. Bilateral damage to the mammillo-thalamic tract impairs recollection but not familiarity in the recognition process: A single case investigation. Neuropsychologia 45: 2467-2479.

Carlesimo GA, Lombardi MG, Caltagirone C. 2011. Vascular thalamic amnesia: A reappraisal. Neuropsychologia (in press).

Carmichael ST, Price JL. 1995. Limbic connections of the orbital and medial prefrontal cortex in macaque monkeys. J Comp Neurol 363: 615-641.

Carrera E, Michel P, Bogousslavsky J. 2004. Anteromedian, central, and posterolateral infarcts of the thalamus. Stroke 35: 2826-2831.

Cassaday HJ, Rawlins JNP. 1995. Fornix-fimbria section and working memory deficits in rats: Stimulus complexity and stimulus size. Behav Neurosci 4: 594-606.

Castaigne P, Lhermitte F, Buge A, Escourolle R, Hauw JJ, Lyon-Caen O. 1981. Paramedian thalamic and midbrain infarcts: Clinical and neuropathological study. Ann Neurol 10: 127-148.

Caulo M, van Hecke J, Toma L, Ferretti A, Tartaro A, Colosimo C, Romani GL, Uncini A. 2005. Functional MRI study of diencephalic amnesia in Wernicke-Korsakoff syndrome. Brain 128: 1584-1594.

Charles DP, Gaffan D, Buckley MJ. 2004. Impaired recency judgments and intact novelty judgments after fornix transection in monkeys. J Neurosci 24: $2037-2044$.

Chudasama Y, Bussey TJ, Muir JL. 2001. Effects of selective thalamic and prelimbic cortex lesions on two types of visual discrimination and reversal learning. Eur J Neurosci 14: 1009-1020.

Cipolotti L, Husain M, Crinion J, Bird CM, Khan SS, Lossef N, Howard RS, Leff AP. 2008. The role of the thalamus in amnesia: A tractography, high resolution MRI and neuropsychological study. Brain 46: 2745-2758.

Clark RE, Zola SM, Squire LR. 2000. Impaired recognition memory in rats after damage to the hippocampus. I Neurosci 20: $8853-8860$.

Clarke S, Assal G, Bogousslavsky J, Regli F, Townsend DW, Leenders KL, Blecic S. 1994. Pure amnesia after unilateral left polar thalamic infarct: Topographic and sequential neuropsychological and metabolic (PET) correlations. J Neurol Neurosurg Psychiat 57: 27-34.

Cross L, Bashir ZI, Brown MW, Warburton EC. 2010. Roles of prefrontal cortex and mediodorsal thalamus in recognition memory. FENS Abs 5: 115.29. http://fens2010.neurosciences.asso.fr/abstracts/rpdf4/ a115_29.pdf.

Daum I, Ackermann H. 1994. Frontal-type memory impairment associated with thalamic damage. Int I Neurosci 77: 187-198.

Denby C, Vann SD Tsivilis SD Aggleton JP Roberts N Montaldi D Mayes AR. 2009. Mammillary body volume estimation in healthy control subjects and colloid cyst surgery patients. Am J Neurorad 30: 736-743.

DeVito JL. 1980. Subcortical projections to the hippocampal formation in squirrel monkey (Saimiri sciureus). Brain Res Bull 5: 285-289.

Diana RA, Yonelinas AP, Ranganath C. 2007. Imaging recollection and familiarity in the medial temporal lobe: A three-component model. Trends Cogn Sci 11: 379-386.

Dix SL, Aggleton JP. 1999. Extending the spontaneous preference test of recognition: Evidence of object-location and object-context recognition. Behav Brain Res 99: 191-200.

Dusoir H, Kapur N, Byrnes DP, McKinstry S, Hoare RD. 1990. The role of diencephalic pathology in human memory disorder: Evidence from a penetrating paranasal brain injury. Brain 113: 1695-1706.

Edelstyn NMJ, Ellis SJ, Jenkinson P, Sawyer A. 2002. Contribution of the left dorsomedial thalamus to recognition memory: A neuropsychological case study. Neurocase 8: $442-452$.

Edelstyn NMJ, Hunter B, Ellis SJ. 2006. Bilateral dorsolateral thalamic lesions disrupt conscious recollection. Neuropsychologia 44: 931-938.

Eichenbaum H, Yonelinas AP, Ranganath C. 2007. The medial temporal lobe and recognition memory. Ann Rev Neurosci 30: 123-152.

Ennaceur A, Aggleton JP. 1997. The effects of neurotoxic lesions of the perirhinal cortex combined to fornix transection on object recognition memory in the rat. Behav Brain Res 88: 181-193.

Ennaceur A, Delacour J. 1988. A new one-trial test for neurobiological studies of memory in rats. 1: Behavioral data. Behav Brain Res 31: 47-59.

Ennaceur A, Neave NJ, Aggleton JP. 1996. Neurotoxic lesions of the perirhinal cortex do not mimic the behavioural effects of fornix transection in the rat. Behav Brain Res 80: 9-25.

Ennaceur A, Neave NJ, Aggleton JP. 1997. Spontaneous object recognition and object location memory in rats: The effects of lesions in the cingulate cortices, the medial prefrontal cortex, the cingulum bundle, and the fornix. Exp Brain Res 113: 509-519.

Fahy FL, Riches IP, Brown MW. 1993. Neuronal signals of importance to the performance of visual recognition memory tasks: Evidence from recordings of single neurons in the medial thalamus of primates. Progr Brain Res 95: 401-416.

Fazio F, Perani D, Gilardi MC, Colombo F, Cappa SF, Vallar G, Bettinardi V, Paulesu E, Alberoni M, Bressi S, et al. 1992. Metabolic impairment in human amnesia: A PET study of memory networks. J Cereb Blood Flow Metab 12: $353-358$

Fernandez G, Tendolkur I. 2006. The rhinal cortex: "Gatekeeper" of the declarative memory system. Trends Cogn Sci 10: 358-362.

Finger S, Koehler PJ, Jagella C. 2004. The Monakow concept of diaschisis. Arch Neurol 61: 283-288.

Gaffan D. 1994a. Dissociated effects of perirhinal cortex ablation, fornix transection, and amygdalectomy: Evidence for multiple memory systems in the primate temporal lobe. Exp Brain Res 99: 411-422.

Gaffan D. 1994b. Scene-specific memory for objects: A model of episodic memory impairment in monkeys with fornix transection. J Cog Neurosci 6: $305-320$.

Garden D, Massey PV, Caruana DA, Johnson B, Warburton EC, Aggleton JP, Bashir ZI. 2009. Anterior thalamic lesions stop synaptic plasticity in retrosplenial cortex slices: Expanding the pathology of diencephalic amnesia. Brain 132: 1847-1857.

Ghika-Schmid F, Bogousslavsky J. 2000. The acute behavioral syndrome of anterior thalamic infarction: A prospective study of 12 cases. Ann Neurol 114: $1581-1590$.

Gold JJ, Squire LR. 2006. The anatomy of amnesia: Neurohistological analysis of three new cases. Learn Mem 13: 699-710.

Gower EC. 1989. Efferent projections from limbic cortex of the temporal pole to the magnocellular medial dorsal nucleus in the rhesus monkey. I Comp Neurol 280: 343-358.

Graff-Radford NR, Tranel D, van Hoesen GW, Brandt JP. 1990. Diencephalic amnesia. Brain 113: 1-25.

Gratton-Smith PJ, Morris JGL, Shores EA, Batchelor J, Sparks RS. 1992. Neuropsychological abnormalities in patients with pituitary tumors. Acta Neurol Scand 86: 626-631.

Groenewegen HJ. 1988. Organization of the afferent connections of the mediodorsal thalamic nucleus in the rat, related to the mediodorsal-prefrontal topography. Neuroscience 24: 379-431.

Groenewegen HJ, Berendse HW. 1994. The specificity of the non-specific midline and intralaminar thalamic nuclei. Trends Neurosci 17: $52-57$.

Harding A, Halliday G, Caine D, Kril J. 2000. Degeneration of anterior thalamic nuclei differentiates alcoholics with amnesia. Brain 123: $141-154$.

Hildebrandt H, Mueller S, Bussmann-Mork B, Goebel S, Eilers N. 2001. Are some memory deficits unique to lesions of the mamillary bodies? J Clin Exp Neuropsych 23: 490-501.

Hsu DT, Price JL. 2007. Midline and intralaminar thalamic connections with the orbital and medial prefrontal networks in macaque monkeys. J Comp Neurol 504: 89-111.

Hunt PR, Aggleton JP. 1991. Medial dorsal thalamic lesions and working memory in the rat. Behav Neural Biol 55: 227-246.

Hunt PR, Aggleton JP. 1998a. An examination of the spatial working memory deficit following neurotoxic medial dorsal thalamic lesions in rats. Behav Brain Res 97: 129-141.

Hunt PR, Aggleton JP. 1998b. Neurotoxic lesions of the dorsomedial thalamus impair the acquisition but not the performance of delayed matching to place by rats: A deficit in shifting response rules. J Neurosci 18: $10045-10052$

Insausti R, Amaral DG, Cowan WM. 1987. The entorhinal cortex of the monkey: III. Subcortical afferents. J Comp Neurol 264: 396-408.

Isaac CL, Holdstock JS, Cezayirli E, Roberts JN, Holmes CJ, Mayes AR. 1998 Amnesia in a patient with lesions limited to the dorsomedial thalamic nucleus. Neurocase 4: 497-508.

Jenkins TA, Dias R, Amin E, Brown MW, Aggleton JP. 2002. Fos imaging reveals that lesions of the anterior thalamic nuclei produce widespread limbic hypoactivity in rats. J Neurosci 22: 5230-5238.

Jenkins TA, Vann SD, Amin E, Aggleton JP. 2004. Anterior thalamic lesions stop immediate early gene activation in selective laminae of the retrosplenial cortex: Evidence of covert pathology in rats? Eur J Neurosci 19: 3291-3304

Joyce EM, Rio DE, Ruttiman UE, Rohrbaugh JW, Martin PR, Rawlings RR, Eckardt MJ. 1994. Decreased cingulate and precuneate glucose utilization in alcoholic Korsakoff's syndrome. Psychiat Res 54: $225-239$.

Kapur N, Scholey K, Moore E, Barker S, Mayes A, Brice J, Fleming J. 1994. The mammillary bodies revisited: Their role in human memory functioning. In Neuropsychological explorations of memory and cognition: Essays in honor of Nelson Butters (ed. L Cermak), pp. 159-189. Plenum Press, New York.

Kapur N, Crewes H, Wise R, Abbott P, Carter M, Millar J, Lang D. 1998. Mammillary body damage results in memory impairment but not amnesia. Neurocase 4: 509-517. 
Kievet J, Kuypers HGJM. 1977. Organization of the thalamo-cortical connections to the frontal lobe in the rhesus monkey. Exp Brain Res 29: 299-322.

Kishiyama MM, Yonelinas AP, Kroll NEA, Lazzara MM, Nolan EC, Jones EG, Jagust WJ. 2005. Bilateral thalamic lesions affect recollection- and familiarity-based recognition and memory judgments. Cortex 41: $778-788$.

Kopelman MD, Thomson AD, Guerrini I, Marshall EJ. 2009. The Korsakoff syndrome: Clinical aspects, psychology, and treatment. Alcohol Alcohol 44: $148-154$.

Kritchevsky M, Graff-Radford NR, Damasio AR. 1987. Normal memory after damage to medial thalamus. Arch Neurol 44: 959-962.

Levasseur M, Baron J-C, Sette G, Legalt-Demare F, Pappata S, Mauguiere F, Benoit N, Dinh ST, Degos JD, Laplane D, et al. 1992. Brain energy metabolism in bilateral paramedian thalamic infarcts. Brain 115: 795-807.

Mair RG, Hembrook JR. 2008. Memory enhancement with event-related stimulation of the rostral intralaminar thalamic nuclei. J Neurosci 28: 14293-14300.

Mair WGP, Warrington EK, Weiskrantz L. 1979. Memory disorder in Korsakoff's psychosis. A neuropathological and neuropsychological investigation of two cases. Brain 102: 749-783.

Mandler G. 1980. Recognizing: The judgment of prior occurrence. Psych Rev 87: 252-271.

Manns JR, Stark CEL, Squire LR. 2000. The visual paired-comparison task as a measure of declarative memory. Proc Natl Acad Sci 97: 12375-12379.

Markowitsch HJ. 1982. Thalamic mediodorsal nucleus and memory: A critical evaluation of studies in animals and man. Neurosci Biobehav Rev 6: $351-380$.

Mayes AR, Meudell PR, Mann D, Pickering A. 1988. Location of lesions in Korsakoff's syndrome: Neuropsychological and neuropathological data on two patients. Cortex 24: $367-388$.

McAlonan GM, Robbins TW, Everitt BJ. 1993. Effects of medial dorsal thalamic and ventral pallidal lesions on the acquisition of a conditioned place preference: Further evidence for the involvement of the ventral striatopallidal system in reward-related processes. Neuroscience 52: 605-620.

McMackin D, Cockburn J, Anslow P, Gaffan D. 1995. Correlation of fornix damage with memory impairment in six cases of colloid cyst removal. Acta Neurochir (Wien) 135: 12-18.

Mennemeier M, Fennell E, Valenstein E, Heilman KM. 1992. Contributions of the left intralaminar and medial thalamic nuclei to memory. Arch Neurol 49: 1050-1058.

Milner B, Corsi P, Leonard G. 1991. Frontal-lobe contributions to recency judgments. Neuropsychologia 29: 601-618.

Mishkin M, Delacour J. 1975. An analysis of short-term visual memory in the monkey. J Exp Psych: Anim Behav Proc 1: 326-334.

Mitchell AS, Dalrymple-Alford JC. 2005. Dissociable memory effects after medial thalamus lesions in the rat. Eur J Neurosci 22: 973-985.

Mitchell AS, Dalrymple-Alford JC. 2006. Lateral and anterior thalamic lesions impair independent memory systems. Learn Mem 13: 388-396.

Mitchell AS, Dalrymple-Alford JC, Christie MA. 2002. Spatial working memory and the brainstem cholinergic innervation to the anterior thalamus lesions in the rat. J Neurosci 22: 1922-1928.

Mitchell AS, Browning PGF, Baxter MG. 2007. Neurotoxic lesions of the medial mediodorsal nucleus of the thalamus disrupt reinforcer devaluation effects in rhesus monkeys. J Neuroscience 27: 11289-11295.

Montaldi D, Spencer TJ, Roberts N, Mayes AR. 2006. The neural system that mediates familiarity memory. Hippocampus 16: $504-520$.

Moran JP, Dalrymple-Alford JC. 2003. Perirhinal cortex and anterior thalamic lesions: Comparative effects on learning and memory. Behav Neurosci 117: 1326-1341.

Mumby DG, Pinel JPL. 1994. Rhinal cortex lesions and object recognition in rats. Behav Neurosci 108: 11-18.

Mumby DG, Pinel JPL, Dastur FN. 1993. Mediodorsal thalamic lesions and object recognition in rats. Psychobiol 21: 27-36.

Murray EM, Mishkin M. 1986. Visual recognition in monkeys following rhinal cortical ablations combined with either amygdalectomy or hippocampectomy. J Neurosci 6: 1991-2003.

Murray EM, Mishkin M. 1998. Object recognition and location in monkeys with excitotoxic lesions of the amygdala and hippocampus. J Neurosci 18: $6568-6582$

Owen MJ, Butler SR. 1984. Does amnesia after transection of the fornix in monkeys reflect abnormal sensitivity to proactive interference? Behav Brain Res 14: $163-192$.

Paller KA, Acharya A, Richardson BC, Plaisant O, Shimamura AP, Reed BR, Jagust WJ. 1997. Functional neuroimaging of cortical dysfunction in alcoholic Korsakoff's syndrome. J Cog Neurosci 9: 277-293.

Parker A, Gaffan D. 1997a. Mammillary body lesions in monkeys impair object-in-place memory: Functional unity of the fornix-mamillary system. J Cog Neurosci 9: 512-521.
Parker A, Gaffan D. 1997b. The effect of anterior thalamic and cingulate cortex lesions on object-in-place memory in monkeys. Neuropsychologia 35: $1093-1102$.

Parker A, Gaffan D. 1998. Interaction of frontal and perirhinal cortices in visual object recognition memory in monkeys. Eur J Neurosci 10: 3044-3057.

Parker A, Eacott MJ, Gaffan D. 1997. The recognition memory deficit caused by mediodorsal thalamic lesion in non-human primates: A comparison with rhinal cortex lesion. Eur J Neurosci 9: 2423-2431.

Parkin AJ, Dunn JC, Lee C, O'Hara PF, Nussbaum L. 1993. Neuropsychological sequelae of Wernicke's encephalopathy in a 20-year-old woman: Selective impairment of a frontal memory system. Brain Cogn 21: 1-19.

Parkin AJ, Rees JE, Hunkin NM, Rose PE. 1994. Impairment of memory following discrete thalamic infarction. Neuropsychologia 32: $39-51$.

Pepin EP, Auray-Pepin L. 1993. Selective dorsolateral fronted lobe dysfunction associated with diencephalic amnesia. Neurology 43: $733-741$.

Poirier GL, Aggleton JP. 2009. Post-surgical interval and lesion location within the limbic thalamus determine extent of retrosplenial cortex immediate-early gene hypoactivity. Neuroscience 160: 452-469.

Poirier GL, Shires KL, Sugden D, Amin E, Thomas K, Carter DA, Aggleton JP. 2008. Anterior thalamic lesions produce chronic and profuse transcriptional de-regulation in retrosplenial cortex: A model of retrosplenial hypoactivity and covert pathology. Thalamus Related Sys 4: $59-77$.

Quamme JR, Yonelinas AP, Widamen KF, Kroll NEA, Sauve MJ. 2004. Recall and recognition in mild hypoxia: Using covariance structural modeling to test competing theories of explicit memory. Neuropsychologia 42: 672-691.

Ray JP, Price JL. 1993. The organization of projections from the mediodorsal nucleus of the thalamus to orbital and medial prefrontal cortex in macaque monkeys. J Comp Neurol 337: 1031.

Reed LJ, Lasserson D, Marsden P, Stanhope N, Stevens T, Fernando B, Kingsley D, Colchester A, Kopelman MD. 2003. FDG-PET findings in the Wernicke-Korsakoff syndrome. Cortex 39: 1027-1045.

Russchen FT, Amaral DG, Price JL. 1987. The afferent input to the magnocellular division of the mediodorsal thalamic nucleus in the monkey, Macaca fascicularis. J Comp Neurol 256: 175-210.

Saunders RC. 1983. Some experiments on memory involving the fornix-mammillary system. PhD thesis, University of Oxford, UK.

Saunders RC, Aggleton JP. 2007. Origin and topography of fibers contributing to the fornix in macaque monkeys. Hippocampus 17: $396-411$.

Saunders RC, Mishkin M, Aggleton JP. 2005. Projections from the entorhinal cortex, perirhinal cortex, presubiculum, and parasubiculum to the medial thalamus in macaque monkeys: Identifying different pathways using disconnection techniques. Exp Brain Res 167: 1-16.

Sauvage M, Fortin NJ, Owens CB, Yonelinas AP, Eichenbaum H. 2008. Recognition memory opposite effects of hippocampal damage on recollections and familiarity. Nat Neurosci 11: 16-18.

Sauvage M, Beer Z, Eichenbaum H. 2010. Recognition memory: Adding a response deadline eliminates recollection but spares familiarity. Learn Mem 17: 104-108.

Shaw C, Aggleton JP. 1995. Evidence for the independence of recognition and recency memory in amnesic subjects. Cortex 31: 57-71.

Sherman SM. 2007. The thalamus is more than just a relay. Curr Opin Neurobiol 17: 417-422

Shrivalkar P, Seth M, Schiff ND, Herrera DG. 2006. Cognitive enhancement with central thalamic electrical stimulation. Proc Natl Acad Sci 103: 17007-17012.

Simons JS, Spiers HJ. 2003. Prefrontal and medial temporal lobe interactions in long-term memory. Nat Rev Neurosci 4: 637-648.

Soei E, Koch B, Schwarz M, Daum I. 2008. Involvement of the human thalamus in relational and nonrelational memory. Eur J Neurosci 28: $2533-2541$.

Squire LR, Amaral DG, Zola-Morgan S, Kritchevsky M, Press G. 1989. Description of brain injury in the amnesiac patient N.A based on magnetic resonance imaging. Exp Neurol 105: 23-35.

Squire LR, Wixted JT, Clark RE. 2007. Recognition memory and the medial temporal lobe: A new perspective. Nat Rev Neurosci 8: 872-883.

Sziklas V, Petrides M. 1993. Memory impairments following lesions to the mammillary region of the rat. Eur J Neurosci 5: 525-540.

Taube JS. 2007. The head direction signal: Origins and sensory motor integration. Ann Rev Neurosci 30: 181-207.

Tsanov M, Wright N, Vann SD, Erichsen J, Aggleton JP, O'Mara SM. 2011. Differential regulation of synaptic plasticity of the hippocampal and the hypothalamic inputs to the anterior thalamus. Hippocampus 21: $1-8$.

Tsivilis D, Vann SD, Denby C, Roberts N, Mayes AR, Montaldi D, Aggleton JP. 2008. A disproportionate role for the fornix and 
mammillary bodies in recall vs. recognition memory. Nat Neurosci 11: $834-842$.

Van der Werf YD, Weerts JGE, Jolles J, Witter MP, Lindeboom J, Scheltens Ph. 1999. Neuropsychological correlates of a right unilateral lacunar thalamic infarction. J Neurol Neurosurg Psychiat 66: 36-42.

Van der Werf YD, Witter MP, Uylings HBM, Jolles J. 2000. Neuropsychology of infarctions in the thalamus: A review. Neuropsychologia 39: 613-627.

Van der Werf YD, Witter MP, Groenewegen HJ. 2002. The intralaminar and midline nuclei of the thalamus. Anatomical and functional evidence for participation in processes of arousal and awareness. Brain Res Rev 39: $107-140$.

Van der Werf YD, Jolles J, Witter MP, Uylings HBM. 2003a. Contributions of thalamic nuclei to declarative memory functioning. Cortex 39: $1047-1062$.

Van der Werf YD, Scheltens P, Lindeboom J, Witter MP, Uylings HBM, Jolles J. 2003b. Deficits of memory, executive functioning, and attention following infarction in the thalamus; a study of 22 cases with localized lesions. Neuropsychologia 41: 1330-1344.

Vann SD. 2009. Gudden's ventral tegmental nucleus is vital for memory: Re-evaluating diencephalic inputs for amnesia. Brain 132: 2372-2384.

Vann SD, Aggleton JP. 2004. The mammillary bodies-two memory systems in one? Nat Rev Neurosci 5: 35-44.

Vann SD, Albasser MM. 2009. Hippocampal, retrosplenial, and prefrontal hypoactivity in a model of diencephalic amnesia: Evidence towards an interdependent subcortical-cortical memory network. Hippocampus 19: $1090-1102$.

Vann SD, Saunders RC, Aggleton JP. 2007. Distinct, parallel pathways link the medial mammillary bodies to the anterior thalamus in macaque monkeys. Eur J Neurosci 26: 1575-1586.

Vann SD, Denby C, Love S, Montaldi D, Renowden S, Coakham HB. 2008. Memory loss resulting from fornix and septal damage: Impaired supra-span recall but preserved recognition over a 24-hour delay. Neuropsychology 22: 658-668.

Vann SD, Tsivilis D, Denby CE, Quamme J, Yonelinas AP, Aggleton JP, Montaldi M, Mayes AR. 2009a. Impaired recollection but spared familiarity in patients with extended hippocampal system damage: Convergence across three methods. Proc Natl Acad Sci 106: 5442-5447.

Vann SD, Aggleton JP, Maguire EA. 2009b. What does the retrosplenial cortex do? Nat Rev Neurosci 10: 792-802.

Vertes RP, Hoover WB, Di Prisco GV. 2004. Theta rhythm of the hippocampus: Subcortical control and functional significance. Behav Cogn Neurosci Rev 3: 173-200.

Vertes RP, Hoover WB, Szigetti-Buck K, Leranth C. 2007. Nucleus reuniens of the midline thalamus: Link between the medial prefrontal cortex and the hippocampus. Brain Res Bull 71: 601-609.

Victor M, Adams RD, Collins GH. 1971. The Wernicke-Korsakoff Syndrome, 1st ed. FA Davis, Philiadelphia, PA.

Von Cramon DY, Hebel N, Schuri U. 1985. A contribution to the anatomical basis of thalamic amnesia. Brain 108: 993-1008.

Von Monokow C. 1911. Lokalisation der Hirnfunktionen. J Psychologie Neurologie 17: 185-200.
Voss JL, Paller KA. 2009. An electrophysiological signature of unconscious recognition memory. Nat Neurosci 12: 349-355.

Warburton EC, Aggleton JP. 1999. Differential deficits in the Morris water maze following cytotoxic lesions of the anterior thalamus and fornix transection. Behav Brain Res 98: 27-38.

Warburton EC, Brown MW. 2010. Findings from animals concerning when interactions between perirhinal cortex, hippocampus, and medial prefrontal cortex are necessary for recognition memory. Neuropsychologia 48: 2262-2272.

Warburton EC, Baird AL, Morgan A, Muir JL, Aggleton JP. 2000. Disconnecting hippocampal projections to the anterior thalamus produces deficits on tests of spatial memory in rats. Eur J Neurosci 12: $1714-1726$.

Warburton EC, Morgan A, Baird A, Muir JL, Aggleton JP. 2001. The conjoint importance of the hippocampus and anterior thalamic nuclei for allocentric spatial learning: Evidence from a disconnection study in the rat. J Neurosci 21: 7323-7330.

Warrington EK. 1984. The Recognition Memory Test. NFER-Nelson, Windsor, UK.

Wilton LAK, Baird AL, Muir JL, Honey RC, Aggleton JP. 2001. Loss of the thalamic nuclei for "head direction" produces impaired spatial memory in rats. Behav Neurosci 115: 861-869.

Wolff M, Gibb SJ, Dalrymple-Alford JC. 2006. Beyond spatial memory: The anterior thalamus and memory for the temporal order of a sequence of odor cues. J Neurosci 26: 2907-2913.

Wolff M, Gibb SJ, Cassel JC, Dalrymple-Alford JC. 2008. Anterior but not intralaminar thalamic nuclei support allocentric spatial memory. Neurobiol Learn Mem 90: 71-80.

Wright N, Erichsen JT, Vann SD, O'Mara S, Aggleton JP. 2010. Parallel but separate inputs from limbic cortices to the mammillary bodies and anterior thalamic nuclei in the rat. J Comp Neurol 518: $2334-2354$

Yeterian EH, Pandya DN. 1989. Thalamic connections of the cortex of the superior temporal sulcus in the rhesus monkey. J Comp Neurol 282: $80-97$.

Yonelinas AP. 2002. The nature of recollection and familiarity: A review of 30 years of research. J Mem Lang 46: 441-517.

Zhu XO, Brown MW, McCabe BJ, Aggleton JP. 1995. Effects of the novelty or familiarity of visual stimuli on the expression of the intermediate early gene c-fos in the rat brain. Neuroscience 69: 821-829.

Zola-Morgan S, Squire LR. 1985. Amnesia in monkeys after lesions of the mediodorsal nucleus of the thalamus. Ann Neurol 17: 558-564.

Zola-Morgan S, Squire LR, Amaral DG. 1989. Lesions of the hippocampal formation but not lesions of the fornix or the mammillary nuclei produce long-lasting memory impairment in monkeys. J Neurosci 9: 898-913.

Zoppelt D, Koch B, Schwarz M, Daum I. 2003. Involvement of the mediodorsal nucleus in mediating recollection and familiarity. Neuropsychologia 41: 1160-1170.

Received December 15, 2010; accepted in revised form March 13, 2011. 


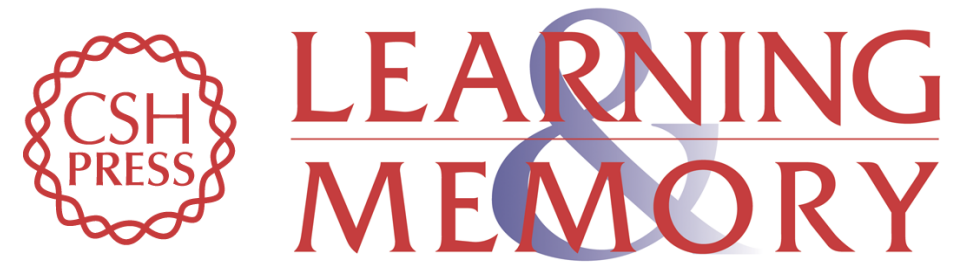

\section{Unraveling the contributions of the diencephalon to recognition memory: A review}

John P. Aggleton, Julie R. Dumont and Elizabeth Clea Warburton

Learn. Mem. 2011, 18:

Access the most recent version at doi:10.1101//m.1884611

References This article cites 171 articles, 26 of which can be accessed free at: http://learnmem.cshlp.org/content/18/6/384.full.html\#ref-list-1

License

Email Alerting Receive free email alerts when new articles cite this article - sign up in the box at the Service top right corner of the article or click here. 